IFN Working Paper No. 939, 2012

\title{
A Dynamic Analysis of Entry Regulations and Productivity in Retail Trade
}

Florin Maican and Matilda Orth 


\title{
A Dynamic Analysis of Entry Regulations and Productivity in Retail Trade*
}

\author{
Florin Maican ${ }^{\dagger}$ and Matilda Orth ${ }^{\ddagger}$
}

December 7, 2014

\begin{abstract}
Quantifying possible inefficiencies stemming from regulation is important to both policymakers and researchers. We use a dynamic structural model to evaluate the role of local market entry regulations in the productivity of retail trade. Our model is flexible with respect to how local market regulations influence store productivity and controls for demand in local markets. We combine the structural approach with detailed data on all stores in the Swedish retail industry. The results show that more liberal entry regulations increase future productivity and that the increase in productivity is larger for small stores and small markets than for large stores and large markets.
\end{abstract}

Keywords: Retail trade, regulation, imperfect competition, dynamic structural model.

JEL Classification: L11, L81, L88, O30.

${ }^{*}$ We thank the editor, two anonymous referees, Ulrich Doraszelski, John Haltiwanger, Lennart Hjalmarsson, Randi Hjalmarsson, Henrik Horn, Salvador Navarro, Amil Petrin, Saso Polanec, Fabiano Schivardi, and the participants of the EIEF workshop on Structural Approaches to Productivity and Industrial Dynamics 2012 (Rome), IIOC 2011 (Boston), EEA-ESEM 2010 (Glasgow), and the Nordic Retail and Wholesale Conference 2008 (Stockholm) for valuable comments and suggestions. We gratefully acknowledge financial support from the Swedish Retail and Wholesale Development Council, the Torsten Söderberg Foundation, the Jan Wallander and Tom Hedelius Foundation, and the Marianne and Marcus Wallenberg Foundation.

${ }^{\dagger}$ Research Institute of Industrial Economics (IFN) and University of Gothenburg, Box 640, SE-405 30, Göteborg, Sweden, Phone +46-31-786 4866, Fax +46-31-786 1326, E-mail: florin.maican@economics.gu.se

${ }^{\ddagger}$ Research Institute of Industrial Economics (IFN), Box 55665, SE-102 15, Stockholm, Sweden, Phone +46-8-665 4531, Fax +46-8-665 4599, E-mail: matilda.orth@ifn.se 


\section{Introduction}

The impact of regulations on market outcomes is frequently debated in many countries because policy interventions designed to prevent market failure may also lead to inefficiencies. Firm reactions to changes in the market environment depend on firms' productivity levels, which are determined by both internal factors that firms can control and firms' external environment. Yet, little work has attempted to quantify the effect of regulations on productivity (Syverson, 2011). If regulations restrict productivity, both policymakers and researchers must quantify these costs to evaluate the associated changes in welfare and to determine the optimal level of regulation. In this paper, we propose a dynamic structural model to assess the implications of local market entry regulations for the productivity of retail trade.

Isolating and quantifying the effects of entry regulations on productivity requires both careful modeling and comprehensive data. First, entry regulations affect productivity, which must be considered in the estimation of the service production function. Second, retail stores face different incentives to change their productivity in response to regulations depending on their current productivity levels and local market conditions, which in turn affect their future productivity relative to competitors. Any welfare analysis of regulations must consider the full distribution of store responses in local markets. Third, the impact of regulation on productivity must be disentangled from demand shocks, such as increases in market size or structural changes in shopping behavior, to ensure that such shocks are not interpreted as changes in productivity. Fourth, standard problems such as the simultaneity of input choices and selection in the estimation of the service production function and potential endogeneity concerns regarding the stringency of regulations must be considered.

To address these modeling challenges and to accurately measure the effect of regulatory stringency on productivity, we propose a dynamic structural model that 
builds on the growing body of literature on heterogeneity in productivity within industries (Ericson and Pakes, 1995; Olley and Pakes, 1996). ${ }^{1}$ The model employs a controlled productivity process with respect to local market regulation, allows stores to react differently to changes in regulation, and controls for demand in local markets. Importantly, addressing these modeling challenges would be difficult by simply regressing labor productivity (measured as the value-added per full-time adjusted employee) or a measure of multi-factor productivity on a regulation measure. We combine the structural model with rich panel data for all retail stores in Sweden for the 1996-2002 period and perform separate analyses for eleven subsectors.

Our approach is particularly advantageous because we obtain the full distribution of productivity responses for all stores and calculate the change in aggregate weighted productivity from more liberal entry regulation in local markets. This quantification exercise attempts to elucidate an issue of direct policy interest. Further, this framework provides a point of departure for a more complete welfare analysis of local market entry regulations and can be applied to other imperfectly competitive, regulated industries. Because stores cannot influence or form expectations about the future stringency of regulation, we follow a two-step estimation procedure to alleviate endogeneity concerns regarding regulation. Our model captures the net effect of regulation on productivity and provides a clear identification strategy for heterogeneous store responses to regulatory changes, which does not require the assumptions that are necessary in a dynamic game framework. ${ }^{2}$

Various features make the retail industry appropriate for examining the impact of regulation on productivity. First, retail markets are subject to substantial regulation that is more restrictive in Europe than in the U.S. Specifically, in Europe, entry

\footnotetext{
${ }^{1}$ Recent contributions on manufacturing and/or trade include Levinsohn and Petrin (2003); Ackerberg et al. (2006); Ackerberg et al. (2007); De Loecker (2011); Doraszelski and Jaumandreu (2013); and Gandhi et al. (2013).

${ }^{2}$ Such assumptions raise concerns about, for instance, functional forms of cost functions, multiple equilibria, and aggregation to reduce the computational complexity (Pakes et al., 2007; Dunne et al., 2013; Maican and Orth, 2013).
} 
regulation empowers local authorities to govern the entry of new stores. Second, retail trade is thought to substantially contribute to the frequently debated productivity gap between Europe and the U.S. (Gordon, 2004; Schivardi and Viviano, 2011). Examples of productivity improvements in retail trade include the adoption of information technology (e.g., scanners, barcodes, and credit card processing machines), inventory and price management, wholesale and distribution networks, economies of scale and density, intangible assets and skills (e.g., brand recognition, reputation, and human capital), and vertical contracts and integration (Holmes, 2001; Schivardi and Viviano, 2011; Basker, 2012). Third, retail has become increasingly important for overall economic activity in modern economies, currently accounting for up to 6 percent of GDP and 10 percent of employment. Retail markets in both Europe and the U.S. have trended toward fewer, larger stores. Further, in U.S. retail trade, entry and exit explain nearly all labor productivity growth. By contrast, in the manufacturing sector, entry and exit account for approximately 30 percent of total growth (Schmitz, 2005; Foster et al., 2006).

In Sweden, all stores are subject to regulation, providing its 290 municipalities power to make land use decisions. Each potential entrant must submit a formal application to the local government. The decision to change a geographic zoning restriction and thus to allow a store to enter the market requires a consideration of the market structure, price, traffic, and environmental consequences. Such regulation decisions are binding, and local authorities rarely approve all applications.

To measure the stringency of regulation, we draw on previous work on land use and entry regulations and employ rich data that vary across local markets and over time to control for market size and the potential endogeneity of regulation. We consider the number of approved applications divided by the population density, the number of approved applications relative to the number of stores, and the number of approved applications relative to the number of zoning plans (Bertrand and Kramarz, 2002; Schivardi and Viviano, 2011; Sadun, 2014). For robustness, 
we also include index variables with different weights and the number of approved applications (Suzuki, 2013; Turner et al., 2014).

The results show that productivity is higher under more liberal entry regulations and substantial heterogeneity exists in the marginal effects across stores and local markets. Specifically, store productivity increases by 1.8 percent on average per additional approved application across all subsectors. In local markets, the median increase in aggregate productivity from an additional approval is 2-5 percent in four subsectors (textile, footwear, books, and toys) and 0.2-1 percent in the remaining seven subsectors. Moreover, store productivity increases by an additional 1 percentage point for small stores compared with large stores, and aggregate local market productivity increases by an additional 1-2 percentage points in small markets compared with large markets. These results are robust to the use of various semiparametric estimators, the use of different measures of regulation, and the inclusion of controls for the potential endogeneity of regulation. In addition, we find increasing returns to scale in most subsectors of Swedish retail and that it is important to allow for a controlled productivity process, to allow for flexibility in how stores react to regulation, and to control for local market demand and omitted prices. Our findings highlight the non-trivial importance of entry regulation in the productivity of local retail markets.

This paper makes several contributions to the literature. Surprisingly few studies have aimed to examine the importance of regulation for productivity, which is currently a key issue within the productivity literature (Syverson, 2011). To the best of our knowledge, this paper is among the first to utilize a dynamic structural model to quantify the effects of entry regulation on productivity in retail. In doing so, this paper contributes a structural framework to previous research on how regulations affect productivity (Djankov et al., 2002; Syverson, 2011; Greenstone et al., 2012; Buccirossi et al., 2013) and relates to a growing body of literature on land use regulation (Maican and Orth, 2013; Suzuki, 2013; Turner et al., 2014). Further, the 
proposed framework complements the existing retail literature (Bertrand and Kramarz, 2002; Haskel and Sadun, 2011; Schivardi and Viviano, 2011; Sadun, 2014) 3 and contributes to recent work on productivity dynamics in retail (Foster et al., 2006; Basker, 2007; Basker, 2012). This study's strengths include the structural framework and rich data on all stores across retail industries, which allows for a careful investigation of both dynamics and heterogeneity in store-level responses to changes in entry regulation. The isolation of demand effects from productivity in a local market for services has recently been attempted in a companion paper on retail food (Maican and Orth, 2009), as well as in previous research at the industry level in the manufacturing sector (Klette and Griliches, 1996; Levinsohn and Melitz, 2006; Katayama et al., 2009; De Loecker, 2011; Pozzi and Schivardi, 2012; Doraszelski and Jaumandreu, 2013). ${ }^{4}$ Because of the difficulty of measuring physical output and defining retail prices, both technical and quality-adjusted productivity measures (i.e., true productivity without demand shocks and the sum of technical productivity and remaining demand shocks) should be considered. The proposed framework is general and can be applied to retail and services industries in other countries.

The reminder of the paper proceeds as follows: Section 2 discusses entry regulation and the utilized data. Section 3 provides reduced-form empirical evidence of the effect of entry regulation on productivity. Section 4 describes the modeling approach. Section 5 discusses productivity and the results of the structural model

\footnotetext{
${ }^{3}$ Schivardi and Viviano (2011) find that strict entry regulations hinder productivity in the Italian retail trade. Sadun (2014) finds that an increase in approved applications results in higher employment growth, whereas Haskel and Sadun (2011) find that total factor productivity in retail decreased after the 1996 planning regulation in the U.K. In France, entry regulation is found to slow labor growth (Bertrand and Kramarz, 2002).

${ }^{4}$ Recent research has linked establishment and product-level data on prices and quantities in samples of narrowly defined manufacturing firms (e.g., Petrin and Warzynski, 2012). Relying on only a small sample of retail stores, however, severely limits the evaluation of regulations in local markets. To the best of our knowledge, no study of productivity in retail combines detailed storelevel information and store-level prices for a total population of stores. Griffith and Harmgart (2005), Reynolds et al. (2005), and Maican and Orth (2009) outline the characteristics of retail markets.
} 
of the impact of regulation on productivity. Section 6 concludes. In several places, we refer to an online appendix that contains various analyses that are not discussed in the paper.

\section{Entry regulation and data}

The majority of OECD countries have entry regulations that empower local authorities to make decisions regarding the entry of new stores. Such regulations aim to prevent possible negative externalities regarding, for instance, competition, lack of access for consumers, and environmental aspects. Entry restrictions differ substantially across countries, however. Whereas some countries strictly regulate large entrants, more flexible zoning laws exist, for instance, in the U.S. (Hoj et al., 1995; Pilat, 1997; Boylaud and Nicoletti, 2001; Nicoletti and Scarpetta, 2003; Griffith and Harmgart, 2005; Pilat, 2005).

In Sweden, the Plan and Building Act ("Plan och Bygglagen" or, PBL) empowers the 290 municipalities to process applications for new entrants. Geographical zoning allows municipalities to manage land use, i.e., all stores are subject to this regulation. ${ }^{5}$ Thus, if a store wants to enter a specific local market, it must submit a formal application to the municipality. In processing new entrant applications, local governments must evaluate the market structure, store supply, product assortment, price, and environmental consequences. PBL decisions are binding, and local authorities rarely approve all applications. Inter-municipality issues regarding entry are addressed by the 21 county administrative boards. The PBL is considered a major barrier to entry, resulting in diverse outcomes, such as different price levels across local markets (Swedish Competition Authority, 2001:4). Several reports stress the need for improved analysis of how regulations affect market outcomes (Pi-

\footnotetext{
${ }^{5}$ Although hours of operation are also regulated in some countries, they are not regulated in Sweden.
} 
lat, 1997; Swedish Competition Authority, 2001:4; Swedish Competition Authority, 2004:2). Online Appendix A describes the PBL in greater detail.

Measures of regulation. To measure regulatory stringency in local markets, we collect data from a variety of sources. A limitation of existing research on land use and entry regulations is the absence of an ideal measure of regulation. ${ }^{6}$ Consistent with previous research, we include a number of measures that vary across markets and over time to control for market size and the potential endogeneity of regulation.

The first data set contains the number applications approved by local authorities. We access the number of approved PBL applications that allow the entry of retail stores. The data were collected from surveys of 163 of 290 municipalities for the 1987-1992, 1992-1996, and 1997-2000 periods (Swedish Competition Authority, 2001:4). We also access the total number of PBL approvals for each municipality and year (Swedish Mapping, Cadastral and Land Registration Authority (Lantmäteriet)). The total number of PBL approvals differs from the PBL approvals that allow the entry of retail stores because the total number of PBL approvals includes PBL approvals related to all types of commercial activities (not only retail) and residential purposes. ${ }^{7}$ Both measures of the number of PBL approvals are flow variables, i.e., they capture the number of new applications that are approved. The correlation between these two measures is 0.83. Because of the high correlation, we utilize the data for all approvals (rather than only approvals of new retail stores) to allow for the use all local markets and years.

The second data set contains the total number of zoning plans for each municipality and year (Swedish Mapping, Cadastral and Land Registration Authority (Lantmäteriet)). Each local market is divided into a number of well-defined geographic areas called zoning plans that are subject to entry regulation. The existing

\footnotetext{
${ }^{6}$ Bertrand and Kramarz (2002); Gyourko et al. (2008); Schivardi and Viviano (2011); Suzuki (2013); Sadun (2014) and Turner et al. (2014).

${ }^{7}$ Suzuki (2013) utilizes data on applications for residential purposes to evaluate cost changes in the lodging industry. Our data differ in that we include applications for both commercial and residential purposes, which more closely approximates actual regulation enforcement.
} 
number of zoning plans is a stock variable, i.e., it captures the number of geographic areas for each market-year observation. An approved PBL application can change the number of zoning plans for the following year.

The third data set includes information on the share of seats for each political party in local municipal governments, as the implementation of the PBL depends on the preferences of politicians in local governments (Bertrand and Kramarz, 2002; Schivardi and Viviano, 2011). In particular, non-socialist local governments are expected to apply the PBL more liberally. ${ }^{8}$ The exogeneity of political preferences assumes that land use issues are not decisive in local elections. Indeed, Swedish municipalities have many responsibilities, and spending regarding childcare, education and elder care are more likely to influence voter decisions than entry regulation.

To produce a sound measure of regulation, we must ensure that the number of PBL approvals is comparable across local markets and must control for larger municipalities, which might have a higher number of approvals only because of their size. We construct the following entry regulation measures for each municipality and year: (i) the number of PBL approvals divided by the population density; (ii) the number of PBL approvals divided by the number of stores; (iii) the number of PBL approvals divided by the total number of zoning plans for each municipality and year. In addition, for robustness, we consider (iv) index variables that combine our various data sources ${ }^{9}$ and (v) the number of approvals. The alternative market size measures allow us to evaluate the robustness of our normalization and acknowledge that the number of approvals is proportional to each market size vari-

\footnotetext{
${ }^{8}$ This pattern is contrary to, for instance, France and Italy. It is well established that the Swedish non-socialist government favors liberalization. For example, the non-socialist government has deregulated the pharmacy and telecom markets.

${ }^{9}$ This index draws on previous research on regulation conducted by Suzuki (2013). The index variable includes the share of non-socialist seats in the local government, the number of approvals divided by the number of stores, and the number of approvals divided by the number of zoning plans. The main index variable specification applies half of the weight to the share of non-socialist seats and one-quarter each to both measures of the shares of PBL approvals. Higher regulation index values indicate more liberal regulatory environments. Online Appendix F.2 provides further details on this regulation index variable.
} 
able. The advantage of the regulation measure based on the ratio of PBL approvals to population density is that it captures both market size and geographic density, which are important in retail. Although we present the results of several entry regulation measures, our preferred measure for the main specification is the number of approvals divided by the population density.

If local authorities were to approve all PBL applications, then the number of approvals would measure competition rather than regulation. Although we do not consider the number of rejections, local authorities rarely approve all applications (i.e., there are small local markets), and because the decisions are binding, our measure can capture regulatory stringency. The rate of approval (which requires observations of the number of both approvals and rejections) might be an optimal regulation measure, but this measure is limited in that decisions to apply in a market are a function of the expected success rate.

Local markets. Our modeling approach considers local competition, and market size is determined by subsector, store size, and distance to competitors. We expect the size of local markets to decrease as the durability of goods increases. The 21 counties are most likely too large to reflect local markets, whereas the more than 1,600 localities are most likely too small. However, the 290 municipalities that make entry decisions are a reasonable local market size for the majority of Swedish retail products. Therefore, we define the 290 Swedish municipalities as local markets.

Store and local market data. We use detailed data from Statistics Sweden (SCB) that include all retail stores for the period 1996 to 2002. The unit of observation is the store, which is identified by its tax reporting number. The data include (i) Financial Statistics (FS), which contain input and output measures such as sales, value-added, and investments, and, (ii) Regional Labor Market Statistics (RAMS), which contain number of employees and wages. Most stores consist of one 
unit, but some stores can consist of several units because of, e.g., joint ownership. ${ }^{10}$ If the data include more than one store, we observe total rather than average inputs and outputs. We use all stores that belong to SNI-code 52, "Retail trade, except of motor vehicles and motorcycles; repair of personal household goods." Because we have access to detailed information, we can use five-digit industry codes (a total of 74 for retail). To simplify the presentation and to jointly analyze similar product groups, we consider the following eleven subsectors (discussed in detail in online Appendix B) in the empirical analysis: textiles, clothing, footwear, furniture, electronics, hardware, books, sports, watches, toys, and computers.

SCB provides direct value-added measures. We deflate sales, value-added, investments and capital by sub-groups of the Consumer Price Index (CPI), and we control for subsector prices because subsectors are heterogeneous. Separate subgroups are used for textiles, clothing, footwear, furniture, hardware, books and computers, and for the remaining subsectors, we use the CPI. Finally, we include municipality characteristics, such as population, population density, and income.

Summary statistics. Table 1 presents various summary statistics for the Swedish retail sector during the 1996-2002 period. Total sales increased by 34 percent to 326 billion SEK in 2002. The value-added is 59 billion SEK in 2002, implying an increase of 27 percent since 1996. Over the full period, investment increased by 47 percent to 5 billion SEK. The number of employees (full-time adjusted yearly average) increased from 144,000 to 159,000, i.e., a 10 percent increase. The opposite trend is observed for the number of stores, which decreased by 10 percent during this period. These industry-level statistics indicate pronounced restructuring in the retail industry towards fewer, larger stores. The largest subsector is clothing, followed by furniture and hardware.

Table 2 presents entry and exit rates in local markets by subsector and store

\footnotetext{
${ }^{10}$ Anonymity prevents us from identifying owners and connecting individual units with stores (see online Appendix B for a detailed description of the data). Joint reporting of several stores is likely to occur at headquarters.
} 
size. For example, in the toys subsector, exit rates are high, and large entrants are common. The entry of small stores is most common in clothing, furniture, hardware, and sports. Hardware and sports are the only subsectors that exhibit net entry, whereas all other subsectors exhibit net exit. The highest outflow of stores is observed in textiles, books, and footwear.

The median local market approves 10 PBL applications per year (Table 3). The median number of approvals by number of stores is 0.076 , whereas the median number of approvals by the population density is 0.123 . All the entry regulation measures show considerable variation across local markets and over time. The approvals divided by the number of stores and the approvals divided by the number of zoning plans is approximately twice as large in the 75th percentile market as in the 25th percentile market. The corresponding difference is up to five times larger for the number of approvals by the population density.

Table 4 shows that the entry regulation measures are positively correlated, with correlations varying between 0.22 and $0.52 .{ }^{11}$ Further, markets with more liberal regulation, as measured by the number of approvals divided by the population density, have more stores per capita (0.27) and lower Herfindahl index [HHI] values $(-0.10)$ than other markets. ${ }^{12}$ Table 5 displays the regression results for the local competition measures, the HHI and the entry rate, with each of the regulation measure, local market controls, and year and subsector fixed effects included as explanatory variables. The results indicate that more liberal regulation decreases the HHI and increases entry rates. These results provide evidence of a positive and

\footnotetext{
${ }^{11}$ Municipalities with a non-socialist majorities approved more applications. The correlation between the share of non-socialist seats and the number of approved applications is 0.45 . The corresponding correlation is 0.25 for the number of approvals divided by the number of zoning plans, and the correlations for the regulation index variables range between 0.74 and 0.87 .

${ }^{12}$ The HHI, which is constructed by using market shares based on store sales, and entry rates are calculated for each subsector, local market, and year. The number of approvals divided by the number of zoning plans is positively correlated with the entry rate $(0.06)$. The number of approvals divided by the population density is negatively correlated with the entry rate, income, and income growth, likely because rural markets with low population density have lower incomes and entry rates. The other regulation measures are positively correlated with income and income growth.
} 
statistically significant relationship between more liberal regulation and competition in local markets.

\section{Reduced-form evidence}

To document the empirical relationship between entry regulation and productivity, we present explanatory regressions that include both labor and multi-factor productivity. These reduced-form specifications include three measures of entry regulation: (i) the number of PBL approvals divided by the population density, (ii) the number of PBL approvals divided by the number of stores, and (iii) the number of PBL approvals divided by the number of zoning plans.

\subsection{Labor productivity}

We define labor productivity as the store value-added per full-time adjusted employee and estimate regressions on the pooled sample of all stores and subsectors. Table 6 displays the results for two specifications for regulation measures (i)-(iii) using OLS estimator with standard errors clustered by local market. ${ }^{13}$ The first specification includes a one-year lagged measure of regulation, income growth, population, population density, and fixed effects for years and subsectors as explanatory variables, whereas the second specification includes dummies for the percentiles of average local market income.

The coefficient for regulation is positive and statistically significant in both specifications, indicating that labor productivity increases with more liberal regulation. The coefficient for income growth is also positive and statistically significant. Most other local market characteristics are significant with expected signs, highlighting

\footnotetext{
${ }^{13}$ The results are robust to the use of different levels of clustering for the standard errors. Appendix $\mathrm{C}$ provides additional results from reduced-form regressions for labor and multi-factor productivity.
} 
the importance of controlling for local demand in estimation of productivity. Overall, the results indicate that store labor productivity is higher in markets with more liberal regulatory environments. This finding is robust to the inclusion of several control variables, such as subsector and year fixed effects, and the use of alternative measures of regulation.

\subsection{Multi-factor productivity}

In this subsection, we analyze the effect of entry regulation on a measure of multifactor productivity obtained from a simple service generating function using the OLS estimator, i.e., $\omega_{j t}=y_{j t}-\hat{\beta}_{0}-\hat{\beta}_{l} l_{j t}-\hat{\beta}_{k} k_{j t}$, where $y_{j t}$ is the log of value-added for store $j$ in year $t, l_{j t}$ is the log of the number of full-time adjusted employees, and $k_{j t}$ is the $\log$ of the capital stock. ${ }^{14}$ In this case, multi-factor productivity, $\omega_{j t}$, includes both technical productivity and correlated demand shocks. We then regress store multi-factor productivity on a one-year lagged measure of regulation, while controlling for local market covariates and fixed effects for years and subsectors.

Table 6 presents the regression results, which mirror those presented for labor productivity using pooled data. We find a clear, positive relationship between more liberal regulation and multi-factor productivity (productivity and demand). The coefficient for regulation is positive for all regulation measures and is statistically significant for two of three regulation measures (the number of approvals divided by the population density and the number of approvals divided by the number of stores). ${ }^{15}$

This simple identification strategy for the impact of regulation on productivity suffers from at least two weaknesses, however. First, it relies on the strong assumption that regulation is uncorrelated with the error term in the service generating function, which includes demand shocks and correlated shocks across local markets

\footnotetext{
${ }^{14}$ Capital stock is defined as $K_{t+1}=(1-\delta) K_{t}+I_{t}$, where $\delta$ is the deprecation rate and $I_{t}$ measures the difference between real gross expenditures on capital and gross retirement of capital.

${ }^{15}$ Standard errors are clustered at the local market level.
} 
related to entry regulation. Therefore, we must separate the demand shocks from productivity by modeling both demand and productivity. Second, this identification strategy abstracts from the correlation in store productivity over time and the dynamic effects of regulation on productivity.

Overall, the benchmark results for both labor and multi-factor productivity provide evidence of a positive relationship between more liberal regulation and store productivity. However, a dynamic structural model is needed to allow for flexibility in how regulation influences productivity, to model a controlled productivity process, and to disentangle the effect of regulation on productivity from that on demand.

\section{A dynamic structural model of productivity and regulation}

Stores maximize their expected discounted profits and choose inputs and investments based on current productivity $\omega_{j t}$, capital stock $k_{j t}$, wages $w_{j t}$, and other exogenous observed local market characteristics. ${ }^{16}$ Store productivity follows a controlled first-order Markov process, $P\left(d \omega_{j t} \mid \omega_{j t-1}, r_{m t-1}\right)$, where $r_{m t-1}$ measures entry regulation in local market $m$ during period $t-1$. Two stores that exhibit the same current productivity but that exist in markets with different regulations will differ in their future productivity realizations because they face different incentives to improve their productivity given the stringency of regulation. More liberal regulation might result in better distributions of future productivity, conditional on current productivity, i.e., $P(\cdot)$ is stochastically increasing in $r_{m t-1}$ for a given $\omega_{j t-1}$. The service production function for store $j$ is

$$
q_{j t}=\tilde{\beta}_{l} l_{j t}+\tilde{\beta}_{k} k_{j t}+\tilde{\omega}_{j t}+\tilde{e}_{j t},
$$

\footnotetext{
${ }^{16}$ Lowercase letters represent variables in logs.
} 
where $q_{j t}$ is the $\log$ of service output by store $j$ at time $t$, and $\tilde{\beta}_{l}$ and $\tilde{\beta}_{k}$ are the true technology parameters. ${ }^{17}$ The unobserved $\tilde{\omega}_{j t}$ is technical productivity, and $\tilde{e}_{j t}$ represents shocks to service output that are not predictable during the period in which inputs can be adjusted and in which stores make exit decisions.

In services industries such as retail, measuring service output is difficult. The best proxy for service output is value-added, which controls for the stock of products that are bought from wholesalers. However, value-added implies that we will underestimate the labor and capital parameters without controlling for prices (Klette and Griliches, 1996; Foster et al., 2008). ${ }^{18}$ Based on the available Swedish data, we assume that the demand function has a negative slope and that stores operate in a market with horizontal product differentiation, where $\eta_{s}(<-1$ and finite) captures the elasticity of substitution among products in subsector $s$ :

$$
p_{j t}=p_{s t}+\frac{1}{\eta_{s}} q_{j t}-\frac{1}{\eta_{s}} q_{s m t}-\frac{1}{\eta_{s}} \xi_{j t}
$$

where $p_{j t}$ is the log of service output price for store $j, p_{s t}$ is the log of service output price in subsector $s, q_{s m t}$ is the log of service output in subsector $s$ in local market $m$, and $\xi_{j t}$ represents demand shocks to store $j$. Using (2) to control for prices in (1), we obtain

$$
y_{j t}=\beta_{l} l_{j t}+\beta_{k} k_{j t}-\beta_{q} q_{s m t}-\frac{1}{\eta_{s}} \xi_{j t}+\omega_{j t}+e_{j t},
$$

where $y_{j t}=q_{j t}+p_{j t}-p_{s t}$ is deflated value-added; $\beta_{l, k}=\left(1+\frac{1}{\eta_{s}}\right) \tilde{\beta}_{l, k}$ are the coefficients for labor and capital, respectively; $\beta_{q}=\frac{1}{\eta_{s}}$ is the coefficient for market

\footnotetext{
${ }^{17}$ Service output does not include the products that are purchased from the wholesaler and sold in the store, i.e., intermediate inputs. This model is easy to apply to a general specification. For example, translog with neutral efficiency across stores would perform equally well.

${ }^{18}$ If products are perfect substitutes, deflated sales are a perfect proxy for unobserved qualityadjusted output. In manufacturing, Foster et al. (2008) analyze the relationships among physical output, revenue, and firm-level prices in the context of market selection and find that productivity based on physical quantities is negatively correlated with store-level prices, whereas productivity based on revenue is positively correlated with store-level prices.
} 
output; and $\omega_{j t}=\left(1+\frac{1}{\eta_{s}}\right) \tilde{\omega}_{j t}$ and $e_{j t}=\left(1+\frac{1}{\eta_{s}}\right) \tilde{e}_{j t}$ are technical productivity and shocks to service production adjusted for the elasticity of demand, respectively. We use aggregate value-added in subsector $s$ in local market $m$ as a proxy for $q_{s m t}$ (Klette and Griliches, 1996). When estimating (3), we must control for unobserved demand shocks $\xi_{j t}$ and unobserved productivity shocks $\omega_{j t}$. This demand system allows for one elasticity of substitution for all stores within each subsector, i.e., a constant markup over marginal cost by subsector $s,\left(\frac{\eta_{s}}{1+\eta_{s}}\right)$, and the Lerner index is $\frac{1}{\left|\eta_{s}\right|}$.

The nature of the available data and the difficulty of measuring prices in retail require that we use a simple demand system, and we argue that our empirical application supports a constant elasticity of demand (CES) demand system. ${ }^{19}$ The Swedish retail industry has characteristics reflecting monopolistic competition, i.e., each local market consists of many stores such that a price change in one store likely has a minor impact on the market price and the regulation process. Most local markets consist of 5-12 stores per subsector, and there are no local monopolies. We analyze each store as a separate unit. Thus, we focus on the substantial share of stores operating as independent or franchise units. ${ }^{20}$

To control for unobserved demand shocks, we decompose $\xi_{j t}$ into two parts, $\xi_{j t}=\mathbf{z}_{m t}^{\prime} \boldsymbol{\beta}_{z}+u_{j t}^{d}$, where $\mathbf{z}_{m t}^{\prime}$ represents the observed local demand characteristics (population, population density and income) and $u_{j t}^{d}$ represents the remaining unobserved, store-specific demand shocks. In addition, we remove the immediate effect of regulation on prices by including current regulation $r_{m t}$ in $\mathbf{z}_{m t}^{\prime}$. Controlling

\footnotetext{
${ }^{19} \mathrm{~A}$ common and well-known challenge in retail studies is the measurement of prices owing to the complexity of products and product assortments. In our setting, measuring prices is even more difficult because we recover productivity for all stores, which requires separate price measures for each store. We are not aware of any study on retail productivity and market structure that combines detailed store-level information for all stores and store-level prices.

${ }^{20} \mathrm{~A}$ careful and complete demand analysis applying the Berry et al. (1995) (BLP) framework requires store-level price data and product characteristics for all stores, which is unfortunately unavailable in many datasets.
} 
for unobserved demand shocks in (3), we obtain

$$
y_{j t}=\beta_{l} l_{j t}+\beta_{k} k_{j t}-\beta_{q} q_{s m t}-\frac{1}{\eta_{s}} \mathbf{z}_{m t}^{\prime} \boldsymbol{\beta}_{z}-\frac{1}{\eta_{s}} u_{j t}^{d}+\omega_{j t}+e_{j t} .
$$

To identify technical productivity separately from demand, we assume that $u_{j t}^{d}$ are i.i.d. shocks and that collapse into $e_{j t}$. If there are correlated demand shocks, $u_{j t}^{d}$ enters in $\omega_{j t}$, and we identify quality-adjusted productivity, i.e., the sum of technical productivity and remaining demand shocks (see online Appendix D). An important difference between technical and quality-adjusted productivity is the interpretation of the results, i.e., the remaining demand shocks that are included in $\omega_{j t}$. For simplicity, we refer to $\omega_{j t}$ as productivity in what follows, even if we might measure quality-adjusted productivity.

Regulation and the productivity process. Regulation influences the productivity of incumbent stores with a one-year lag that reflects the time required for stores to cut slack and change features, such as management, to increase their productivity. ${ }^{21}$ The reduced-form empirical evidence for labor productivity and multi-factor productivity presented in Section 3 (Table 6) supports the modeling of regulation in the productivity process. Productivity $\omega_{j t}$ follows a first-order controlled Markov process:

$$
\omega_{j t}=E\left[\omega_{j t} \mid \omega_{j t-1}, r_{m t-1}\right]+v_{j t}=g\left(\omega_{j t-1}, r_{m t-1}\right)+v_{j t},
$$

where $r_{m t-1}$ measures entry regulation in local market $m$ during period $t-1$ and $v_{j t}$ represent shocks to productivity that are mean independent of all information known at $t$. Shocks $v_{j t}$ can be understood as the realization of uncertainties that are naturally linked to productivity. The conditional expectation function $E\left[\omega_{j t} \mid \omega_{j t-1}, r_{m t-1}\right]$ is unobserved by the econometrician (but known to the store) and is approximated by the nonparametric function $g\left(\omega_{j t-1}, r_{m t-1}\right)$.

\footnotetext{
${ }^{21}$ For example, similar approaches are adopted to analyze productivity and R\&D (Aw et al., 2011; Doraszelski and Jaumandreu, 2013) as well as productivity and trade liberalization (De Loecker, 2011).
} 
A key advantage of our model over models in previous work on regulation and productivity is that regulation affects store productivity in a flexible manner, i.e., $g\left(\omega_{j t-1}, r_{m t-1}\right)$ captures the differential impact of more liberal regulation on store productivity conditional on both productivity and the stringency of local market regulation. After observing the regulation level, stores immediately adjust their prices to secure their market share and customers as captured by $r_{m t}$ in $\mathbf{z}_{m t}^{\prime}$. The lagged effect of regulation is on productivity. In the case of quality-adjusted productivity, the previous degree of local market regulation $r_{m t-1}$ affects both prices and productivity, and these effects cannot be separated from one another.

Mechanism for the impact of entry regulation on productivity. We expect more liberal regulation to influence productivity in several ways. Entry regulations can improve productivity directly if new stores are highly productive. Moreover, because entry regulations constitute barriers to entry, we expect reduced regulatory stringency to increase competition. Incumbents then face incentives to increase their productivity to survive and to maintain their market share (X-inefficiency), reflecting an indirect effect of entry regulation on productivity. Stores can increase their productivity in several ways, such as investments in new technology (e.g., scanner techniques, distribution centers) and improvements in management. ${ }^{22} \mathrm{We}$ provide reduced-form evidence of a positive relationship between regulation and competition measures in our data. Table 5 presents the regression results for the entry rate and HHI with different regulation measures, local market controls, and year and subsector fixed effects included as explanatory variables. The coefficient for regulation is positive and statistically significant at the 1 percent level in all specifications. The results indicate that a positive relationship exists between competition and regulation, suggesting that this mechanism might play a role in our data.

\footnotetext{
${ }^{22}$ Goolsbee and Syverson (2008) provide an example how the threat of entry influences incumbent behavior.
} 
Incumbent responses to changes in regulatory stringency are complex in retail, relating to, for instance, store type, product assortment, hours of operation, prices, distribution systems, new investments, and education. Modeling these responses requires a complex setting based on dynamic games. This paper aims to measure the net effect of entry regulation on productivity rather than to model all channels through which this effect occurs. The advantage of a single agent framework is that it allows for an improved understanding of store heterogeneity. By contrast, endogenizing competition by considering strategic interactions in a dynamic game framework markedly complicates the analysis and imposes additional assumptions (Pakes et al., 2007; Dunne et al., 2013; Maican and Orth, 2013). ${ }^{23}$

Entry regulation is exogenous in the productivity process such that individual stores do not affect the outcome of regulation or form expectations about the stringency of future regulation. Although we employ a two-step estimation procedure (as discussed below), which alleviates endogeneity concerns regarding regulation, we examine the robustness of our findings by using an instrumental variable approach in the controlled Markov regression. We discuss the endogeneity of regulation in the estimation and robustness sections. ${ }^{24}$

Productivity and labor demand. To estimate the service production function (4), we must proxy for unobserved productivity. To recover productivity from the service production function (4), we use the labor demand function from each store profit maximization problem and a good measure of store-specific wages, i.e., $l_{j t}=\tilde{l}_{t}\left(\omega_{j t}, k_{j t}, w_{j t}, q_{s m t}, \mathbf{z}_{m t}\right)$, where $\tilde{l}_{t}(\cdot)$ is an unknown function strictly increasing in $\omega_{j t}$, and $w_{j t}$ is the log of the wage rate at the store level (Levinsohn and Petrin, 2003; Doraszelski and Jaumandreu, 2013). Assuming that labor is a static

\footnotetext{
${ }^{23}$ For example, dynamic games raise issues about the functional forms of cost functions, multiple equilibria, equilibrium selection mechanisms, and aggregation to reduce computational complexity. Concerns about aggregation and computational complexity, for instance, are pertinent in analyses of local retail markets that consist of many stores.

${ }^{24}$ To render regulation endogenous in a structural framework, we need detailed information about regulation in each local market. However, the lack of such institutional details can be substituted with additional modeling assumptions, which we expect to influence the final results.
} 
and variable input based on current productivity is not as restrictive in the retail industry as in many other industries. Indeed, part-time employment is common, the share of skilled labor is relatively low, and stores frequently adjust their labor use according to variation in customer flows. ${ }^{25}$

We assume that wages follow an exogenous process. The scalar unobservable assumption, i.e., that productivity $\omega_{j t}$ is the only unobservable in $\tilde{l}_{t}(\cdot)$, is required for identification. The strictly increasing condition mentioned above also holds under the simple CES demand system (Levinsohn and Melitz, 2006). Because stores set wages and because both part-time and temporary contracts are common in retail, the identification relies on variation in store-specific wages.

Estimation. The estimation of the service production function proceeds in two steps. By inverting the labor demand function to recover productivity and by substituting this function into the service production function, we obtain $y_{j t}=$ $\phi_{t}\left(l_{j t}, k_{j t}, w_{j t}, q_{s m t}, \mathbf{z}_{m t}\right)+\epsilon_{j t}$, where $\epsilon_{j t}$ is the sum of demand and output shocks and $\phi_{t}(\cdot)=\beta_{l} l_{j t}+\beta_{k} k_{j t}-\beta_{q} q_{s m t}-\frac{1}{\eta_{s}} \mathbf{z}_{m t}^{\prime} \beta_{z}+\omega_{j t}$. In the first step, we estimate $\hat{\phi}_{t}(\cdot)$, which separates productivity $\omega_{j t}$ from i.i.d. shocks to output $\epsilon_{j t}$ according to $\omega_{j t}(\boldsymbol{\beta})=\hat{\phi}_{t}(\cdot)-\beta_{l} l_{j t}-\beta_{k} k_{j t}+\beta_{q} q_{s m t}+\frac{1}{\eta_{s}} \mathbf{z}_{m t}^{\prime} \boldsymbol{\beta}_{z}$, where $\boldsymbol{\beta}=\left(\beta_{l}, \beta_{k}, \beta_{q}, \eta_{s}, \boldsymbol{\beta}_{z}\right){ }^{26}$

In the second step, we non-parametrically regress $\omega_{j t}(\boldsymbol{\beta})$ on a polynomial expansion of order three in $\omega_{j t-1}(\boldsymbol{\beta})$ and $r_{m t-1}$ to obtain shocks $v_{j t}$. The moment $E\left[v_{j t} \mid l_{j t-1}\right]=0$ identifies $\beta_{l}$. The assumption that stores determine their capital investments at $t-1$ implies that the coefficient for capital $\beta_{k}$ is identified by $E\left[v_{j t} \mid k_{j t}\right]=0$. Parameters $\eta_{s}$ and $\boldsymbol{\beta}_{z}$, are identified by $E\left[v_{j t} \mid q_{s m t-1}\right]=0$ and $E\left[v_{j t} \mid \mathbf{z}_{m t-1}\right]=0$, respectively. When local entry regulation $r_{m t}$ is a component of $\mathbf{z}_{m t}$, a moment based on $r_{m t}$ can be used to identify the coefficient for $r_{m t}{ }^{27}$

\footnotetext{
${ }^{25}$ Online appendix E considers a static and parametric labor demand function (Doraszelski and Jaumandreu, 2013).

${ }^{26}$ We use a third-order polynomial expansion in its arguments and estimate $\hat{\phi}_{t}(\cdot)$ by using OLS.

${ }^{27}$ Nevertheless, we cannot truly separate the effect of regulation on prices, as regulation might have lagged effects on prices. If one is concerned that current regulation is correlated with shocks to the service production function $\epsilon_{j t}$ and demand in the first step of the estimation, one can use moments based on $r_{m t-1}$ or the average stringency of regulation in other local markets.
} 
The identification of the impact of entry regulation on productivity relies on current productivity shocks $v_{j t}$ being mean independent of regulation in the previous period. The nature of the structural semiparametric model helps address the possible endogeneity of regulation on productivity. Further, removing the effect of current regulation and other local market characteristics from the sum of demand and production shocks $\epsilon_{j t}$ in the first step reduces endogeneity concerns in the second step (i.e., when estimating the productivity process) and clarifies our identification of the impact of entry regulation on productivity. However, if the remaining productivity shocks $v_{j t}$ are still correlated with regulation in the previous period (e.g., they include demand shocks correlated with the regulation measure), we might overestimate the impact of more liberal regulation on productivity. In this case, we can identify the coefficient for regulation in the second step by using moment conditions based on Hausman-type instruments (Hausman, 1997), e.g., average regulatory stringency in other local markets. ${ }^{28}$

The $\boldsymbol{\beta}$ parameters are estimated by minimizing the sample analogue of the moment conditions discussed above. Because nonlinearities exist in the coefficients, we use the Nelder-Mead numerical optimization method to minimize the GMM objective function

$$
\min _{\boldsymbol{\beta}} Q_{N}=\left[\frac{1}{N} W^{\prime} v(\boldsymbol{\beta})\right]^{\prime} A\left[\frac{1}{N} W^{\prime} v(\boldsymbol{\beta})\right],
$$

where $A$ is the weighting matrix defined as $A=\left[\frac{1}{N} W^{\prime} v(\boldsymbol{\beta}) v^{\prime}(\boldsymbol{\beta}) W\right]^{-1}$ and $W$ is the matrix of instruments. Using the estimated $\hat{\boldsymbol{\beta}}$ coefficients, we obtain the recovered productivity, $\omega_{j t}=y_{j t}-\hat{\beta}_{l} l_{j t}-\hat{\beta}_{k} k_{j t}+\hat{\beta}_{q} q_{s m t}+\frac{1}{\hat{\eta}_{s}} \mathbf{z}_{m t}^{\prime} \hat{\boldsymbol{\beta}}_{z} \cdot{ }^{29}$

\footnotetext{
${ }^{28}$ Our empirical results are robust to the use of Hausman-type instruments to control for the possible endogeneity of regulation.

${ }^{29}$ One can also recover productivity based on estimates using the labor demand function, $\omega_{j t}=$ $\hat{\phi}_{t}(\cdot)-\hat{\beta}_{l} l_{j t}-\hat{\beta}_{k} k_{j t}+\hat{\beta}_{q} q_{s m t}+\frac{1}{\hat{\eta}_{s}} \mathbf{z}_{m t}^{\prime} \hat{\boldsymbol{\beta}}_{z}$. Although mean productivity is similar, the greater variance is expected with the service production function. To compare the results across various proxy estimators, much of the previous productivity research provides results based on production functions, e.g., Olley and Pakes (1996), Ackerberg et al. (2006), and De Loecker (2011).
} 


\subsection{Service production function estimates}

Table 7 presents the results from the service production function estimates for each subsector. We focus on the OLS estimator and main specification $\left(\mathrm{NP}_{l m}\right)$, which employs a controlled Markov process for productivity and controls for both prices and local market conditions. Returns to scale $\left(\beta_{l}+\beta_{k}\right)$ are higher after we control for prices (Klette and Griliches, 1996). ${ }^{30}$ For all subsectors, the labor coefficient $\left(\beta_{l}\right)$ is smaller after we control for prices in the main specification (column (2) in Table 7) than in the OLS specification, which indicates that we have successfully controlled for simultaneity bias. In the main specification, the book, computer and electronic subsectors exhibit the highest labor elasticity, whereas the book and furniture subsectors exhibit the highest capital elasticity.

The average estimated demand elasticity across subsectors in $\mathrm{NP}_{l m}$ is -4.12 , with a range between -8.30 (hardware) and -1.26 (watches). The corresponding average markup (price over marginal cost) across subsectors is 1.86 , with a range between 1.13 (hardware) and 4.76 (watches). These findings are consistent with previous results based on U.S. data (Hall, 1988). A high degree of product differentiation might explain the low values (in absolute terms) of demand elasticity in some subsectors, such as furniture. Clothing, electronics, and sports are characterized by relatively low markups and high exit rates (Table 2). The estimated parameters allow us to compute productivity and to evaluate the impact of entry regulation on productivity by using the estimated Markov process.

\footnotetext{
${ }^{30}$ The returns to scale are higher after we control for prices in $\mathrm{NP}_{l m}$ than in the OLS specification and the nonparametric specification without price controls ( $\mathrm{NP}_{l}$ in online Appendix F.2). Our results are consistent with extant research showing increasing returns to scale in retail. We expect increasing returns to scale in services owing to geographic dispersion, multi-market contact, and an increasing returns to scale "illusion" that is attributable to self-services, i.e., the volume of self-services is larger than the amount of services performed by stores (Ofer, 1973). Few studies use production function approaches to analyze returns to scale in retail trade, though Ofer (1973), Bairam (1994) and Maican and Orth (2009) are exceptions.
} 


\section{Results of the structural analysis}

Based on the estimated productivity of each store, we quantify the changes in productivity with more liberal regulation. Specifically, we analyze store productivity for the pooled sample (Section 5.1), store productivity by subsector (Section 5.2), aggregate productivity in local markets (Section 5.3), and heterogeneity in productivity depending on both store and market size (Section 5.4). We then provide robustness checks (Section 5.5).

\subsection{Store-level productivity}

Before turning to the results for the specification that is fully consistent with our dynamic model, we pool all stores and subsectors and estimate the following simple linear specifications by using the OLS estimator: (a) an $A R(1)$ productivity process, $\omega_{j t}=\alpha_{0}+\alpha_{1} \omega_{j t-1}+\alpha_{r} r_{m t-1}+f_{t}+f_{s}+\nu_{j t} ; \quad$ and (b) $\omega_{j t}=$ $\alpha_{0}+\alpha_{r} r_{m t-1}+\mathbf{z}_{m t} \boldsymbol{\alpha}_{z}+f_{t}+f_{s}+\mu_{j t}$, where $\nu_{j t}$ and $\mu_{j t}$ are i.i.d shocks that are not correlated with entry regulation $r_{m t-1}$ or local market characteristics $\mathbf{z}_{m t}$. In addition, the $f_{t}$ and $f_{s}$ are fixed effects for year and subsector, respectively. The first specification includes previous productivity, controls for the persistence of productivity, and extends the analysis from Section 3 by allowing regulation to exert a dynamic effect on productivity.

We use estimated store productivity from our main specification $N P_{l m}$ (Section 4) and the OLS estimator (Section 3.2). The same regulation measures and control variables from the reduced-form regressions presented in Table 6 are utilized. The results allow us to connect the reduced-form regressions with the specification that is entirely consistent with the dynamic model presented in Section 5.2. ${ }^{31}$

Table 8 shows that the coefficient for regulation is positive in all specifications

\footnotetext{
${ }^{31}$ Note that specifications (a) and (b) are not entirely consistent with the model $\left(N P_{l m}\right)$ that relies on a flexible approximation of the productivity process based on previous productivity and regulatory stringency.
} 
and statistically significant for all specifications using productivity from our proxy estimator $\left(N P_{l m}\right) .{ }^{32}$ The marginal effects of an additional PBL approval, with population density held constant, increases productivity by an average of 1.67 percent for the OLS specification and 0.42 percent for $N P_{l m}$. The fourfold greater increase for the OLS specification is consistent with the theoretical predictions because this productivity measure includes both productivity and prices. Productivity in $N P_{l m}$ is less persistent than productivity in the OLS estimator, which suggests that we have successfully isolated parts of the persistent demand shocks from $\omega_{j t}$. The structural approach implicitly controls for simultaneity and selection biases that affect productivity measures and marginal effects owing to nonlinearity in the productivity process. Overall, the results of the pooled sample and linear specification provide evidence of a positive association between regulation and store-level multifactor productivity.

\section{$5.2 \quad$ Store-level productivity by subsector}

To quantify the effects of more liberal entry regulation on future store productivity more accurately, we use the regression results from the controlled Markov process and approximate $g\left(\omega_{j t-1}, r_{m t-1}\right)$ by using a third-order polynomial expansion in previous productivity $\omega_{j t-1}$ and regulation $r_{m t-1} \cdot{ }^{33}$ An advantage of our dynamic framework is that we obtain marginal effects for each store in the data, which allows us to recover the full distribution of the effect of entry regulation on productivity in each local market.

To keep the presentation of the structural results tractable, we measure regulation as the number of approvals divided by the population density, which allows for exogeneity and captures both market size and density (both of which are important

\footnotetext{
${ }^{32}$ The standard errors are clustered at the local market level.

${ }^{33} \mathrm{~A}$ liberal regulatory environment does not serve as a productivity growth machine in local markets because increased competition also induces exit, which implies a decrease in product differentiation that negatively affects consumers. Thus, our model only measures the net effect.
} 
in retail). The results are robust to the use of the our alternative measures of regulation discussed in Section 2, i.e., the number of approved PBL applications divided by the number of stores, the number of approved PBL applications divided by the number of zoning plans, the regulation index, and the number of PBL approvals (see online Appendix F).

Table 9 documents the heterogeneity in the change in store productivity with one additional approval (with population density held constant). As the table shows, store productivity is higher when regulation is more liberal. This result holds for all subsectors. Store productivity increases by 1-4 percent on average for most subsectors. In addition, productivity changes vary across stores, as indicated by the standard deviations of the marginal effects. The largest average marginal effects (2-4 percent) of entry regulation on productivity are obtained for toys, footwear, textile, and books. This pattern of results may be due to the relatively high net exit rates in these subsectors, which force incumbents to increase their productivity (Table 2).

We also present the support of the impact of a more liberal regulation on productivity. For each subsector, the support is determined based on 1,000 simulated values from all parts of the productivity distribution. The support provides additional information regarding the heterogeneity of productivity changes with more liberal regulation and complement the mean marginal effects. The large and positive upper bounds in footwear, books, and textiles indicate that some stores realize substantial productivity gains from more liberal regulation in these subsectors and confirm the relatively large mean marginal effects in these subsectors. ${ }^{34}$

\footnotetext{
${ }^{34}$ To investigate the sensitivity of the marginal effects of regulation on productivity in our structural approach, we utilize simulation. The estimated results of the controlled productivity process based on productivity recovered from a service production function with different coefficients for labor and capital than those in our main specification $\left(\mathrm{NP}_{l m}\right)$ exhibit changes in the marginal effects of regulation on productivity. The results of the simulations and the comparison of the nonparametric two-step approach and simple parametric specification emphasize the importance of using sophisticated methods to accurately estimate productivity and to evaluate changes produced by regulation. These simulations are available from the authors upon request.
} 


\subsection{Aggregate local market productivity}

A key task for policymakers is to assess the change in aggregate local market productivity when entry regulation becomes more liberal. Quantifying the cost of regulations in terms of changes in local market productivity is a first step toward a more complete welfare analysis of entry regulations. The magnitude of these effects can thus be compared with other demand and supply side aspects that local authorities should evaluate when considering the consequences of a new entrant. For example, in Sweden, municipalities must consider the availability of stores and store products, prices, market shares, and traffic.

We evaluate the change in aggregate local market productivity in each subsector caused by one additional PBL approval (with population density held constant). To do so, we sum the marginal effect of all stores for each local market and year, which is based on the actual previous level of productivity for stores and level of regulation, with output market shares as weights. The results indicate the change in weighted aggregate local market productivity if regulation were to become more liberal.

Table 10 provides the distribution of annual changes in local market productivity from one additional approval. The effect of regulation exhibits substantial heterogeneity across local markets and subsectors. For example, the textile, electronics, and watches subsectors are characterized by relatively high dispersion of changes in local market productivity with more liberal regulation. The median local market productivity increases by 1-5 percent in the textile, footwear, books, and toys subsectors but only by $0.2-0.6$ percent in the other subsectors. ${ }^{35}$

The large increases in aggregate productivity for the textile, footwear, and book subsectors are clearly connected to high net exit rates (Table 2) and low growth

\footnotetext{
${ }^{35}$ For a median market, 10 applications are approved, which represents a non-trivial change in productivity of 2-56 percent.
} 
in average value-added (Table B.2 in online Appendix B). Further, the increase in aggregate productivity in the toys and computers subsectors is associated with high shares of entry of large stores (in absolute numbers and relative to the share small store entry; Table 2) and high mean growth in value-added and number of employees (Table B.2 in online Appendix B).

\subsection{Heterogeneity across stores and local markets}

A central advantage of our structural framework is that we can obtain the full distribution of marginal effects of more liberal regulation, enabling us to carefully investigate heterogeneous productivity responses across stores and local markets. To evaluate heterogeneity in marginal effects across store sizes, we divide the sample into small and large stores based on the median of the number of employees. Table 11 displays the median marginal effects of one additional approval on small and large store productivity and indicates whether the medians of these groups are equal. As the table shows, an additional PBL approval yields a greater increase in productivity for small stores than for large stores. Specifically, median productivity increases by 1 additional percentage point for small stores compared with large stores. This result holds for seven of the eleven subsectors. The difference in the productivity increase between small and large stores is smaller in the furniture, sports, and hardware subsectors, while approaching zero for the clothing sector.

Because an additional approval increases competition, small incumbents must improve their productivity to a greater extent than larger incumbents to remain in the market. A test of equal median marginal changes in productivity due to more liberal regulation shows that we can reject the null of equal medians between small and large stores for all subsectors. ${ }^{36}$

Heterogeneity in marginal effects across local markets can depend on the market

\footnotetext{
${ }^{36}$ To test whether the medians are equal for small and large stores, we follow recent studies in statistics and use quantile regressions with a group indicator.
} 
size. To investigate the posssible effects of market size, we analyze the weighted aggregate local market productivity in markets with populations below and above the median (Table 11). We find that the increase in aggregate local market productivity increases due to an additional PBL approval is greater in small local markets than in large local markets. Specifically, median local market productivity increases by 1-3 additional percentage points in small markets compared with large markets for the textile, footwear, toys, and watches subsectors. The difference between small and large markets is smaller for the remaining subsectors. ${ }^{37}$

We thus find evidence of larger productivity improvements from more liberal regulation in small markets than in large markets. In other words, allowing a new store to enter the market creates more intense competition in local markets that consist of fewer stores (incumbents) such that the competitive intensity from entrants declines with the number of stores. A test of equal median marginal effects between large and small markets rejects the null of equal medians for ten of the eleven subsectors.

\subsection{Robustness checks}

In this section, we evaluate the sensitivity of our empirical results. For this purpose, we conduct a variety of robustness checks on the results from the service production function and controlled productivity process. Overall, the main results are found to be robust in a large number of specification tests.

Alternative measures of regulation. To demonstrate the robustness of our regulation variable, we consider the following alternative measures of entry regulation: number of PBL approvals divided by the number of stores, number of PBL approvals divided by the number of zoning plans, index variables that combine our

\footnotetext{
${ }^{37}$ We cannot reject the null of equal medians for the electronics subsector. For the computers subsector, the increase in median productivity is greater in large markets than in small markets. This result might be due to the tendency of firms in this industry to locate in large and expanding cities rather than in rural environments.
} 
data sources, and number of PBL applications (see Section 2 for details). All the results are presented in online Appendix F.

First, Tables F.1 and F.2 (online Appendix F.1) present estimates of the service production function and descriptive statistics for the impact of regulation for each subsector when we use the number of approved PBL applications divided by the total number of stores and the number of approved PBL applications divided by the number of zoning plans as entry regulation measures. Table F.3 displays the weighted aggregate marginal effects of an additional approval computed for both regulation measures evaluated at the observed number of stores and number of zoning plans in a market. The findings indicate that the positive impact of more liberal entry regulation on productivity is robust to the use of alternative measures of regulation.

Second, we use the regulation index described in Section 2 and alternative weighting schemes for this regulation index. Online Appendix F.2 presents the marginal effects for individual stores and local markets when the regulation index increases by one standard deviation. The results also indicate that more liberal regulation increases store productivity for virtually all subsectors. Specifically, median store productivity increases by 2-4 percent on average for most subsectors with a one standard deviation increase in the regulation index.

Third, we use the number of PBL approvals to measure the degree of regulation. Online Appendix F.3 presents a detailed analysis of the results with the number of approved PBL applications as the entry regulation measure. The results from using the number of PBL approvals of retail stores for the sample of 163 (of 290) local markets are available from the authors upon request. The results show that the approval of one additional application by local authorities increases the productivity of the median store by 1.5-2.6 percent for most subsectors, which represents a relatively larger effect than that obtained from regulation measures unrelated to 
local market size. ${ }^{38}$ Importantly, our main results regarding the improvement in productivity are robust to the use of a regulation measure that is not normalized by market size. Aggregated across all local markets, this improvement translates to annual subsector economic costs ranging from 2.8 million euros (toys) to 194 million euros (furniture). ${ }^{39}$ These figures are not trivial, corresponding to nearly 10 percent of the annual capital investments made in the Swedish retail trade. For the 1996-2002 period, the aggregate subsector costs range from up to 20 million euros (toys) to 1,361 million euros (furniture). Finally, the positive effect of regulation on productivity is robust to the use of political preferences as a measure of regulatory stringency. ${ }^{40}$.

Endogeneity of regulation. Our proposed framework allows us to control for the possible endogeneity of regulation. In the Markov process regression, we control for the endogeneity of our regulation measures by using the average value of the regulation measures in other local markets as instruments. The use of this type of instrument is valid if regulation is not subject common productivity shocks across local markets. Suzuki (2013) argues that finding a valid instrument for the regulation index is challenging and thus does not control for endogeneity. In our setting, it is important to note that our two-step estimation approach alleviates endogeneity concerns regarding the regulation measure. However, our approach allows us to form moments that control for the possible endogeneity of regulation during both stages of the service production function estimation if endogeneity concerns remain. Furthermore, this approach also allows us to control for the endogeneity of wages and aggregate quantity during the first step of the estimation.

Selection. When we control for selection in our main specification, $\mathrm{NP}_{l m}$ yields

\footnotetext{
${ }^{38}$ This result is expected because the number of approvals is positively correlated with market size.

${ }^{39}$ Numbers are in 2012 values, where $1 \mathrm{EUR}=9.01 \mathrm{SEK}$ and $1 \mathrm{EUR}=1.30 \mathrm{USD}$. In these calculations, we multiply the average annual cost per store by the average number of stores in the subsector over the period 1996-2002.

${ }^{40}$ These results are available from the authors upon request
} 
similar parameter estimates for the service production function and similar magnitudes of the marginal effects of more liberal regulation on productivity (Olley and Pakes, 1996).

Alternative estimators. As noted in the discussion of the results of the service production function estimates, we find evidence that controlling for local market demand and simultaneity bias is crucial, as not controlling for local market demand yields decreasing returns to scale $\left(\mathrm{NP}_{l}\right.$ in Appendix F.2). The service production function parameters change as predicted by theory when we control for simultaneity and prices.

An attractive candidate for proxy of productivity in our nonparametric twostep approach of estimating the service production function is a parametric labor demand function (Doraszelski and Jaumandreu, 2013). As key differences from the main specification, this parametric approach forms moments based on shocks to both service production and demand, and the estimation proceeds in one step. The parametric approach is explained in Appendix E. The main result that more liberal regulation increases productivity holds when we use this parametric approach (the results are available from the authors upon request).

\section{Conclusions}

This paper investigates the impact of regulation on productivity. Although this issue is important to both researchers and policymakers, extant research is still in the initial stages of quantifying the effects of regulation on productivity in various industries. We use a dynamic structural model to estimate multi-factor productivity and to evaluate how it varies with the degree of local market entry regulation in retail trade. Specifically, we analyze how more liberal regulation changes store future productivity and weighted aggregate productivity in local markets. Our model controls for local market demand and allows for different technologies across subsec- 
tors. The advantages of our approach are that we can use a controlled productivity process with respect to regulation and can allow for flexibility in how stores react to regulatory changes by considering the responses of each store. We obtain the full distribution of productivity responses from all stores, which is an important initial step in evaluating the welfare of regulatory changes.

Insight into the extent to which entry regulations affect productivity in retail is particularly important because retail markets have undergone dramatic changes related to the use of technology (e.g., scanners, barcodes, online credit card processing), inventory and price managements, and distribution networks. In addition, structural changes have led to fewer, larger stores. The combination of information technology improvements and economies of scale, density, and scope has dramatically altered the retail sector, which plays an important role in economic activity today. Despite these striking trends, few studies have investigated the effect of local regulations on productivity in local markets by using a structural framework. The proposed approach is general and can be applied to retail and services industries in other countries.

The empirical application relies on detailed data on all stores in Swedish retail market, which is representative of many retail markets in the OECD in terms of market structure and regulation, for the period 1996-2002. The results reveal that there are increasing returns to scale in the majority of subsectors of the Swedish retail industry. Further, substantial heterogeneity in the effect of regulation on productivity is found across stores and local markets. Across all subsectors, store productivity increases by 1.8 percent on average from one additional approved application. In local markets, median aggregate productivity increases by 0.2-5 percent. Moreover, one additional approval increases median productivity by 1 additional percentage point for small stores compared with large stores, and the increase in aggregate local productivity is 1-2 percentage points higher in small markets than in large markets. Our results are robust when we use different measures of regulatory 
stringency and control for the endogeneity of the regulation measure.

Our results are relevant to competition policy through entry regulation in the OECD. We find that more liberal use or design of entry regulations stimulates productivity in local markets. However, these gains must be weighted against environment costs, increased traffic, and access for target consumers, such as pensioners. Our findings contribute to an improved understanding of the frequently debated sources of the productivity gap between Europe and the U.S. 


\section{References}

Ackerberg, D., L. Benkard, S. Berry, and A. Pakes (2007): "Econometric Tools for Analyzing Market Outcomes," Handbook of Econometrics, 6, 4171-4276.

Ackerberg, D., K. Caves, and G. Fraser (2006): "Structural Identification of Production Functions," Mimeo, UCLA.

Ackerberg, D., X. Chen, and J. Hahn (2011): "A Practical Asymptotic Variance Estimator for Two-Step Semiparametric Estimators," Discussion Paper 1803, Cowles Foundation Discussion Paper.

Aw, B. Y., M. J. Roberts, and D. Xu (2011): "R\&D Investment, Exporting, and Productivity Dynamics," American Economic Review, 101(4), 1312-1344.

Bairam, E. (1994): Homogeneous and Nonhomeogeneous Production Functions. Avebury, Ashate Publishing Ltd.

BAsker, E. (2007): "The Causes and Consequences of Wal-Mart's Growth," Journal of Economic Perspectives, 21(3), 177-198.

(2012): "Raising the Barcode Scanner: Technology and Productivity in the Retail Sector," American Economic Journal: Applied Economics, 4(3), 1-27.

Berry, S., J. Levinsohn, and A. Pakes (1995): "Automobile Prices in Market Equilibrium," Econometrica, 63(4), 841-890.

Bertrand, M., and F. Kramarz (2002): "Does Entry Regulation Hinder Job Creation? Evidence from the French retail industry," Quarterly Journal of Economics, 117(4), 1369-1413.

Boylaud, O., and G. Nicoletti (2001): "Regulatory Reform in Retail Distribution," OECD Working Paper 32.

Buccirossi, P., L. Ciari, T. Duso, G. Spagnolo, and C. Vitale (2013): "Competition Policy and Productivity Growth: An Empirical Assessment," Review of Economics and Statistics, 95(4), 1324-1336.

De Loecker, J. (2011): "Product Differentiation, Multi-Product Firms and Estimating the Impact of Trade Liberalization on Productivity," Econometrica, 79(5), $1407-1451$.

Djankov, S., R. La Porta, F. Lopez-de Silanes, and A. Shleifer (2002): "The Regulation of Entry," Quarterly Journal of Economics, CXVII(1), 1-37.

Doraszelski, U., and J. Jaumandreu (2013): "R\&D and Productivity: Estimating Endogenous Productivity," Review of Economic Studies, 80(4), 1338 1383. 
Dunne, T., S. Klimek, M. Roberts, and Y. Xu (2013): "Entry, Exit and the Determinants of Market Structure," The RAND Journal of Economics (forthcoming).

Ericson, R., And A. PAKes (1995): "Markov-Perfect Industry Dynamics: A Framework for Empirical Work," Review of Economic Studies, 62(1), 53-83.

Foster, L., J. Haltiwanger, and C. Krizan (2006): "Market Selection, Reallocation, and Restructuring in the U.S. Retail Trade Sector in the 1990s," Review of Economics and Statistics, 88(4), 748-758.

Foster, L., J. Haltiwanger, and C. Syverson (2008): "Reallocation, Firm Turnover, and Efficiency: Selection on Productivity or Profitability?," American Economic Review, 98(1), 394-425.

Gandhi, A., S. Navarro, and D. Rivers (2013): "On the Identification of Production Functions: How Heterogenous is Productivity?," Mimeo, University of Wisconsin-Madison.

Goolsbee, A., and C. Syverson (2008): "How do Incumbents Respond to the Threat of Entry? Evidence from the Major Airlines," Quartely Journal of Economics, 123(4), 1611-1633.

Gordon, R. (2004): "Why was Europe Left at the Station when America's Productivity Locomotive Departed?," (Working Paper 10661, NBER).

Greenstone, M., J. List, and C. Syverson (2012): "The Effects of Environmental Regulation on the Competitiveness of U.S. Manufacturing," (Working Paper 18392, NBER).

Griffith, R., and H. Harmgart (2005): "Retail Productivity," International Review of Retail, Distribution and Consumer Services, 15(3), 281-290.

Gyourko, J., A. SAiz, and A. Summers (2008): "A New Measure of the Local Regulatory Environment for Housing Markets: The Wharton Residential Land Use Regulatory Index," Urban Studies, 45, 693-729.

Hall, R. (1988): "The Relation between Price and Marginal Cost in U.S. Industry," Journal of Political Economy, 96(5), 921-947.

Haskel, J., And R. SAdun (2011): "Regulation and UK Retailing Productivity: Evidence from Microdata," Economica, 79, 425-448.

Hausman, J. (1997): The Economics of New Goodschap. Valuation of New Goods Under Perfect and Imperfect Competition, pp. 207-248. University of Chicago Press.

Hoj, J., T. Kato, and D. Pilat (1995): "Deregulation and Privatisation in the Service Sector," OECD Working Paper 25. 
Holmes (2001): "Barcodes lead to Frequent Deliveries and Superstores," Rand Journal of Economics, 32(4), 708-725.

Katayama, H., S. Lu, and J. Tybout (2009): "Firm-level Productivity Studies: Illusions and a Solution," International Journal of Industrial Organization, 27(3), 403-413.

Klette, T., And Z. Griliches (1996): "The Inconsistency of Common Scale Estimators when Output Prices are Unobserved and Endogenous," Journal of Applied Econometrics, 11(4), 343-361.

Levinsohn, J., And M. Melitz (2006): "Productivity in a Differentiated Products Market Equilibrium," Mimeo, Harvard University.

Levinsohn, J., And A. Petrin (2003): "Estimating Production Functions Using Inputs to Control for Unobservables," Review of Economic Studies, 70(2), 317341.

Maican, F., And M. Orth (2009): "Productivity Dynamics and the role of "BigBox" Entrants in retailing," Working Paper no. 328, Department of Economics, University of Gothenburg.

(2013): "Entry Regulations, Product Differentiation and Determinants of Market Structure," Mimeo, Reserach Institute of Industrial Economics (IFN) and University of Gothenburg.

Nicoletti, G., and S. Scarpetta (2003): "Regulation, Productivity and Growth: OECD Evidence," Economic Policy, 18(36), 9-72.

Ofer, G. (1973): "Returns to Scale in Retail Trade," Review of Income and Wealth, 19(4), 363-384.

Olley, S., and A. Pakes (1996): "The Dynamics of Productivity in the Telecommunications Equipment Industry," Econometrica, 64(6), 1263-1297.

Pakes, A., S. Berry, and M. Ostrovsky (2007): "Simple Estimators for the Parameters of Dyscrete Dynamic Games, with Entry/Exit Examples," RAND Journal of Economics, 38(2), 373-399.

Petrin, A., And F. Warzynski (2012): "The Impact of Research and Development on Quality, Productivity and Welfare," Mimeo, University of Minnesota.

PILAT, D. (1997): "Regulation and Performance in the Distribution Sector," OECD Working Papers 180.

(2005): "Assessing the Productivity of the UK Retail Sector: Some Further Reflections," The International Review of Retail, Distribution and Consumer Research, 15(3), 291-296.

Pozzi, A., And F. Schivardi (2012): "Demand or Productivity: What determines firm growth?," Mimeo, EIEF Rome. 
Reynolds, J., E. Howard, D. Dragun, B. Rosewell, and P. Ormerod (2005): "Assessing the Productivity of the UK Retail Sector," International Review of Retail, Distribution and Consumer Research, 15(3), 237-280.

Sadun, R. (2014): "Does Planning Regulation Protect Independent Retailers?," Review of Economics and Statistics (forthcoming).

Schivardi, F., and E. Viviano (2011): "Entry Barriers in Retail Trade," Economic Journal, 121(155), 145-170.

Schmitz, J. (2005): "What Determines Productivity? Lessons From the Dramatic Recovery of the U.S. and Canadian Iron Ore Industries Following Their Early 1980s Crisis," Journal of Political Economy, 113(3), 582-625.

Suzuki, J. (2013): "Land Use Regulation as a Barrier to Entry: Evidence from the Texas Lodging Industry," International Economic Review, 54(2), 495-523.

Swedish Competition Authority (2001:4): "Kan Kommunerna Pressa Matpriserna? (Can the Municipalities Put Pressure on Prices?)," Technical Report 4, Stockholm.

(2004:2): "Konsumenterna, Matpriserna och Konkurrensen (Consumers, Retail Food Prices, and Competition)," Technical Report 2, Stockholm.

Syverson, C. (2011): "What Determines Productivity?," Journal of Economic Literature, 49(2), 326-365.

Turner, M., A. Haughwout, and W. van der Klaauw (2014): "Land Use Regulation and Welfare," Econometrica (forthcoming). 
Table 1: Descriptive statistics, Swedish retail trade 1996-2002

\begin{tabular}{|c|c|c|c|c|c|c|c|c|}
\hline & 1996 & 1997 & 1998 & 1999 & 2000 & 2001 & 2002 & $\Delta(\%)$ \\
\hline Sales & 244.0 & 250.0 & 264.0 & 278.0 & 295.0 & 302.0 & 326.0 & 34.0 \\
\hline Value added & 43.1 & 44.7 & 47.8 & 50.0 & 54.8 & 54.9 & 59.2 & 37.0 \\
\hline Investment & 3.4 & 3.4 & 3.6 & 4.5 & 5.3 & 4.8 & 5.0 & 47.0 \\
\hline Capital stock & 10.0 & 11.0 & 12.0 & 15.0 & 17.0 & 19.0 & 20.0 & 100.0 \\
\hline No. of employees & 144.0 & 144.0 & 151.0 & 149.0 & 155.0 & 158.0 & 159.0 & 10.0 \\
\hline No. of stores & $21,464.0$ & $20,787.0$ & $20,318.0$ & $20,085.0$ & $20,169.0$ & $19,618.0$ & $19,233.0$ & -10.0 \\
\hline
\end{tabular}

NOTE: Sales (excl. VAT), value added, investment and capital stock are measured in billions of 1996 SEK

(1 USD=6.71SEK, $1 \mathrm{EUR}=8.63 \mathrm{SEK}$ ). Number of employees is measured in thousands.

Table 2: Entry and exit by subsector 1996-2002

\begin{tabular}{|c|c|c|c|c|c|c|c|c|c|}
\hline \multirow[b]{2}{*}{ Subsector } & \multicolumn{3}{|c|}{ Entry rate } & \multicolumn{3}{|c|}{ Exit rate } & \multirow[b]{2}{*}{ Net entry } & \multirow[b]{2}{*}{ No. of stores } & \multirow[b]{2}{*}{ No. of obs. } \\
\hline & Small & Large & Total & Small & Large & Total & & & \\
\hline \multirow{2}{*}{ Textiles } & 0.071 & 0.007 & 0.078 & 0.129 & 0.007 & 0.136 & -0.055 & 355 & 2,486 \\
\hline & $(0.021)$ & $(0.003)$ & $(0.021)$ & $(0.027)$ & $(0.003)$ & $(0.026)$ & $(0.047)$ & (41) & \\
\hline \multirow[t]{2}{*}{ Clothing } & 0.082 & 0.011 & 0.094 & 0.097 & 0.013 & 0.110 & -0.015 & 2,467 & 17,273 \\
\hline & $(0.014)$ & $(0.001)$ & $(0.016)$ & $(0.014)$ & $(0.003)$ & $(0.015)$ & $(0.021)$ & $(72)$ & \\
\hline \multirow[t]{2}{*}{ Footwear } & 0.063 & 0.008 & 0.071 & 0.093 & 0.011 & 0.104 & -0.033 & 591 & 4,142 \\
\hline & $(0.008)$ & $(0.003)$ & $(0.008)$ & $(0.011)$ & $(0.004)$ & $(0.011)$ & $(0.018)$ & $(41)$ & \\
\hline \multirow[t]{2}{*}{ Furniture } & 0.094 & 0.012 & 0.106 & 0.097 & 0.014 & 0.111 & -0.003 & 1,603 & 11,227 \\
\hline & $(0.016)$ & $(0.003)$ & $(0.015)$ & $(0.018)$ & $(0.005)$ & $(0.020)$ & $(0.019)$ & $(23)$ & \\
\hline \multirow[t]{2}{*}{ Electronics } & 0.066 & 0.007 & 0.073 & 0.087 & 0.009 & 0.096 & -0.023 & 1,291 & 9,037 \\
\hline & $(0.020)$ & $(0.002)$ & $(0.020)$ & $(0.015)$ & $(0.002)$ & $(0.017)$ & $(0.024)$ & $(62)$ & \\
\hline \multirow[t]{2}{*}{ Hardware } & 0.080 & 0.018 & 0.099 & 0.073 & 0.019 & 0.092 & 0.008 & 1,313 & 9,193 \\
\hline & $(0.013)$ & $(0.003)$ & $(0.013)$ & $(0.013)$ & $(0.006)$ & $(0.016)$ & $(0.020)$ & $(22)$ & \\
\hline \multirow[t]{2}{*}{ Books } & 0.062 & 0.009 & 0.071 & 0.100 & 0.016 & 0.116 & -0.044 & 561 & 3,929 \\
\hline & $(0.014)$ & $(0.002)$ & $(0.012)$ & $(0.012)$ & $(0.008)$ & $(0.012)$ & $(0.019)$ & (50) & \\
\hline \multirow[t]{2}{*}{ Sports } & 0.096 & 0.011 & 0.107 & 0.095 & 0.013 & 0.108 & 0.001 & 1,101 & 7,707 \\
\hline & $(0.026)$ & $(0.002)$ & $(0.025)$ & $(0.009)$ & $(0.004)$ & $(0.010)$ & $(0.014)$ & (10) & \\
\hline \multirow[t]{2}{*}{ Watches } & 0.054 & 0.004 & 0.058 & 0.075 & 0.006 & 0.081 & -0.021 & 594 & 4,160 \\
\hline & $(0.019)$ & $(0.004)$ & $(0.019)$ & $(0.016)$ & $(0.004)$ & $(0.015)$ & $(0.019)$ & (26) & \\
\hline \multirow[t]{2}{*}{ Toys } & 0.078 & 0.025 & 0.103 & 0.112 & 0.025 & 0.137 & -0.027 & 228 & 1,599 \\
\hline & $(0.018)$ & $(0.011)$ & $(0.024)$ & $(0.028)$ & $(0.009)$ & $(0.023)$ & $(0.047)$ & (13) & \\
\hline \multirow[t]{2}{*}{ Computers } & 0.112 & 0.025 & 0.137 & 0.108 & 0.031 & 0.139 & -0.001 & 1,176 & 8,237 \\
\hline & $(0.024)$ & $(0.008)$ & $(0.031)$ & $(0.006)$ & $(0.008)$ & $(0.008)$ & $(0.027)$ & $(26)$ & \\
\hline
\end{tabular}

NOTE: The figures represent mean (standard deviation) by subsector and year for the period 1996-2002. Stores are defined as small if the number of employees is below the median and large otherwise. 
Table 3: Local market characteristics

\begin{tabular}{|c|c|c|c|c|c|}
\hline & Mean & Std. dev. & 25 th perc. & Median & 75 th perc. \\
\hline \multicolumn{6}{|l|}{ A. Regulation measures } \\
\hline Number of approved applications & 25.808 & 34.700 & 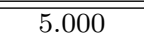 & 10.000 & 28.000 \\
\hline Approvals by number of zoning plans & 0.063 & 0.031 & 0.043 & 0.062 & 0.081 \\
\hline Approvals by number of stores & 0.099 & 0.088 & 0.052 & 0.076 & 0.120 \\
\hline Approvals by population density & 0.278 & 0.703 & 0.044 & 0.123 & 0.267 \\
\hline \multicolumn{6}{|l|}{ B. Other local market characteristics } \\
\hline No of stores & 392.368 & 653.586 & 53.000 & 117.000 & 286.000 \\
\hline No of stores per subsector & 30.873 & 61.069 & 4.000 & 8.000 & 22.000 \\
\hline No of stores per capita & 2.410 & 0.574 & 2.066 & 2.426 & 2.813 \\
\hline Population & 147.933 & 233.067 & 24.314 & 54.426 & 118.581 \\
\hline Population density & 597.600 & 1203.614 & 26.390 & 69.310 & 233.500 \\
\hline Income & 175.178 & 36.752 & 153.401 & 165.668 & 182.341 \\
\hline
\end{tabular}

NOTE: This table displays summary statistics for the regulation measures and other local market characteristics. Municipalities (290 in total) are used as local markets. To measure local market regulation, we use (i) the number of PBL approvals divided by the population density, (ii) the number of PBL approvals divided by the number of stores, and (iii) the number of PBL approvals divided by the total number of zoning plans. Income is the average income at the local market level. Population and income are are reported in thousands of persons and thousands of 1996 SEK. The number of stores per capita is the number of stores per 1,000 people. Population density measures the number of persons per 1,000 $m^{2}$.

Table 4: Correlations between regulation measures and local market characteristics

\begin{tabular}{|c|c|c|c|c|c|c|c|c|}
\hline & $(1)$ & $(2)$ & $(3)$ & $(4)$ & $(5)$ & $(6)$ & $(7)$ & $(8)$ \\
\hline (1) Approvals by number of zoning plans & 1.00 & - & - & - & - & - & - & - \\
\hline (2) Approvals by number of stores & 0.52 & 1.00 & - & - & - & - & - & - \\
\hline (3) Approvals by population density & 0.23 & 0.22 & 1.00 & - & - & - & - & - \\
\hline (4) No of stores per capita & 0.04 & -0.41 & 0.27 & 1.00 & - & - & - & - \\
\hline (5) Income & 0.08 & 0.15 & -0.17 & -0.15 & 1.00 & - & - & - \\
\hline (6) Income growth & 0.11 & 0.01 & -0.03 & 0.02 & 0.45 & 1.00 & - & - \\
\hline (7) Entry rate & 0.06 & -0.02 & -0.04 & 0.04 & 0.03 & 0.01 & 1.00 & - \\
\hline (8) Herfindahl index & -0.07 & 0.21 & -0.10 & -0.20 & -0.09 & -0.04 & -0.05 & 1.00 \\
\hline \multicolumn{9}{|c|}{$\begin{array}{l}\text { NOTE: This table displays the correlations between the regulation measures and local market characteristics. } \\
\text { To measure local market regulation, we use (i) the number of PBL approvals divided by the population } \\
\text { density, (ii) the number of PBL approvals divided by the number of stores, and (iii) the number of PBL } \\
\text { approvals divided by the total number of zoning plans. The Herfindahl index (HHI), which is constructed } \\
\text { using market shares based on store sales, and entry rates are calculated for each subsector, local market, } \\
\text { and year. }\end{array}$} \\
\hline
\end{tabular}


Table 5: Reduced-form regressions: The impact of entry regulation on local market competition

\begin{tabular}{|c|c|c|c|c|c|c|}
\hline & \multicolumn{2}{|c|}{$\begin{array}{l}\text { Number of PBL } \\
\text { approvals divided by } \\
\text { the population density }\end{array}$} & \multicolumn{2}{|c|}{$\begin{array}{l}\text { Number of PBL } \\
\text { approvals divided by } \\
\text { the number of stores }\end{array}$} & \multicolumn{2}{|c|}{$\begin{array}{c}\text { Number of PBL } \\
\text { approvals divided by } \\
\text { the number of zoning plans }\end{array}$} \\
\hline & $\begin{array}{c}\mathrm{HHI} \\
(1)\end{array}$ & $\begin{array}{c}\text { Entry rate } \\
(2)\end{array}$ & $\begin{array}{c}\mathrm{HHI} \\
(1)\end{array}$ & $\begin{array}{l}\text { Entry rate } \\
(2)\end{array}$ & $\begin{array}{l}\text { HHI } \\
(1)\end{array}$ & $\begin{array}{c}\text { Entry rate } \\
(2)\end{array}$ \\
\hline Regulation & $\begin{array}{l}-0.006^{*} \\
(0.004)\end{array}$ & $\begin{array}{l}0.019 * * * \\
(0.004)\end{array}$ & $\begin{array}{l}-0.012 \\
(0.026)\end{array}$ & $\begin{array}{l}0.426^{* * *} \\
(0.035)\end{array}$ & $\begin{array}{l}-0.105^{*} \\
(0.059)\end{array}$ & $\begin{array}{l}0.268^{* * *} \\
(0.074)\end{array}$ \\
\hline Market controls & Yes & Yes & Yes & Yes & Yes & Yes \\
\hline Year FE & Yes & Yes & Yes & Yes & Yes & Yes \\
\hline Subsector FE & Yes & Yes & Yes & Yes & Yes & Yes \\
\hline No. of obs. & 12,528 & 12,528 & 12,528 & 12,528 & 12,528 & 12,528 \\
\hline$R^{2}$ & 0.565 & 0.061 & 0.565 & 0.259 & 0.580 & 0.008 \\
\hline
\end{tabular}

NOTE: Standard errors at the local market level are presented in parentheses. HHI is the Herfindahl index, which is constructed using market shares based on store sales. The HHI and entry rate are calculated for each subsector, local market, and year. Local market controls include population, population density, income, and market fixed effects. To measure local market regulation, we use lagged values of (i) the number of PBL approvals divided by the population density, (ii) the number of PBL approvals divided by the number of stores, and (iii) the number of PBL approvals divided by the total number of zoning plans. Significance: ${ }^{*} \mathrm{p}<0.1$; ${ }^{* *} \mathrm{p}<0.05 ; * * * \mathrm{p}<0.01$. 


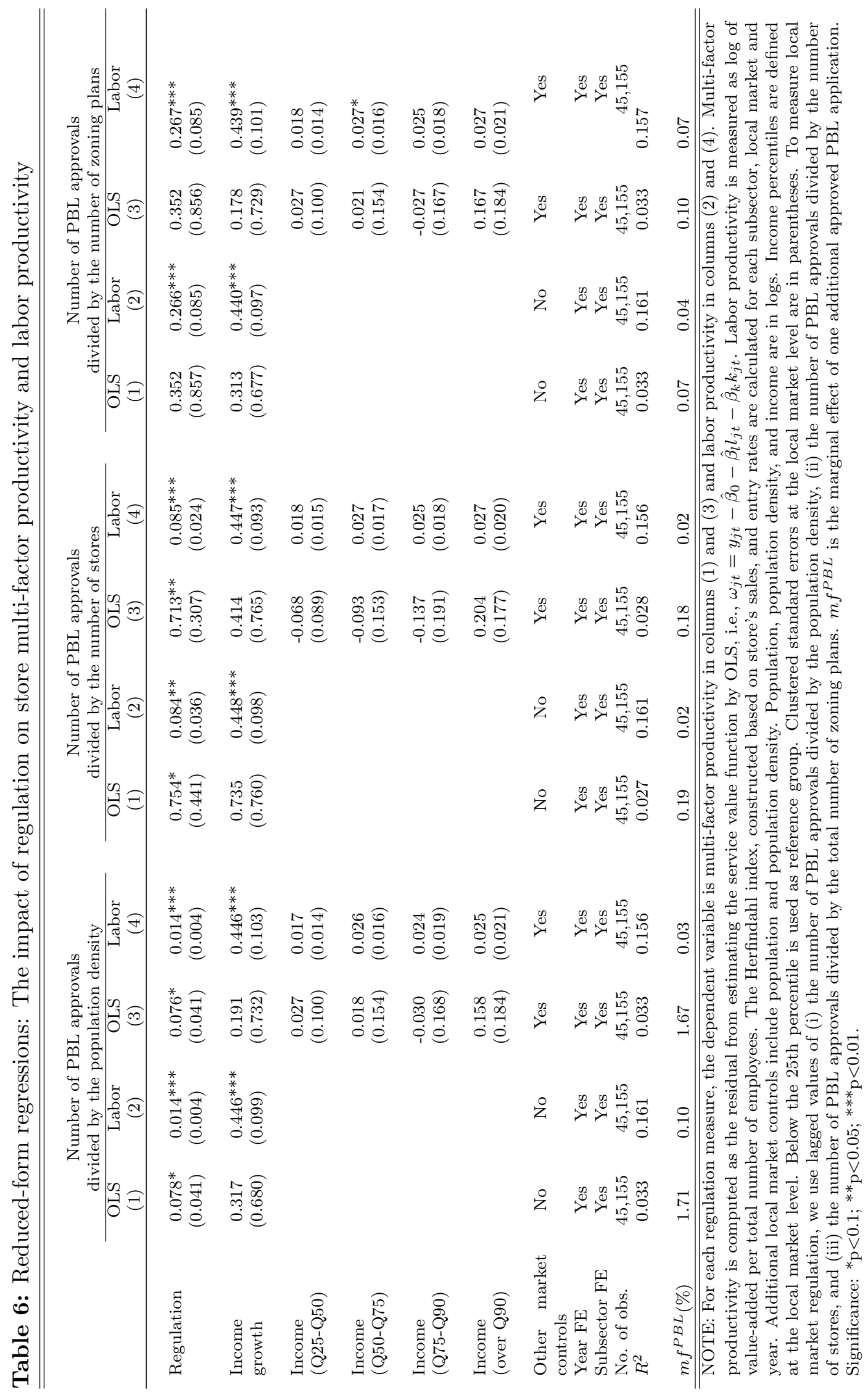


Table 7: Service production function estimates

\begin{tabular}{|c|c|c|c|c|c|c|c|}
\hline & \multicolumn{2}{|c|}{$O L S$} & \multicolumn{4}{|c|}{$N P_{l m}$} & \multirow[b]{2}{*}{ No. of obs. } \\
\hline & $\begin{array}{c}\text { Labor } \\
(1)\end{array}$ & $\begin{array}{c}\text { Capital } \\
\text { (2) }\end{array}$ & $\begin{array}{c}\text { Labor } \\
\text { (1) }\end{array}$ & $\begin{array}{c}\text { Capital } \\
\text { (2) }\end{array}$ & Demand & Markup & \\
\hline Textiles & $\begin{array}{c}0.821 \\
(0.020)\end{array}$ & $\begin{array}{c}0.123 \\
(0.010)\end{array}$ & $\begin{array}{c}0.526 \\
(0.001)\end{array}$ & $\begin{array}{c}0.149 \\
(0.002)\end{array}$ & -5.109 & 1.24 & 1,548 \\
\hline Clothing & $\begin{array}{c}0.757 \\
(0.007)\end{array}$ & $\begin{array}{c}0.120 \\
(0.004)\end{array}$ & $\begin{array}{c}0.675 \\
(0.001)\end{array}$ & $\begin{array}{c}0.127 \\
(0.001)\end{array}$ & -6.960 & 1.16 & 13,308 \\
\hline Footwear & $\begin{array}{c}0.735 \\
(0.011)\end{array}$ & $\begin{array}{c}0.121 \\
(0.006)\end{array}$ & $\begin{array}{c}0.586 \\
(0.003)\end{array}$ & $\begin{array}{c}0.209 \\
(0.001)\end{array}$ & -2.393 & 1.71 & 3,207 \\
\hline Furniture & $\begin{array}{c}0.814 \\
(0.008)\end{array}$ & $\begin{array}{c}0.135 \\
(0.005)\end{array}$ & $\begin{array}{c}0.256 \\
(0.018)\end{array}$ & $\begin{array}{c}0.333 \\
(0.003)\end{array}$ & -1.599 & 2.66 & 8,674 \\
\hline Electronics & $\begin{array}{c}0.821 \\
(0.008)\end{array}$ & $\begin{array}{c}0.144 \\
(0.004)\end{array}$ & $\begin{array}{c}0.557 \\
(0.006)\end{array}$ & $\begin{array}{c}0.097 \\
(0.001)\end{array}$ & -5.462 & 1.22 & 7,087 \\
\hline Hardware & $\begin{array}{c}0.782 \\
(0.007)\end{array}$ & $\begin{array}{c}0.189 \\
(0.004)\end{array}$ & $\begin{array}{c}0.674 \\
(0.008)\end{array}$ & $\begin{array}{c}0.163 \\
(0.005)\end{array}$ & -8.306 & 1.13 & 7,474 \\
\hline Books & $\begin{array}{c}0.737 \\
(0.012)\end{array}$ & $\begin{array}{c}0.149 \\
(0.007)\end{array}$ & $\begin{array}{c}0.502 \\
(0.001)\end{array}$ & $\begin{array}{c}0.129 \\
(0.001)\end{array}$ & -1.654 & 2.52 & 3,054 \\
\hline Sports & $\begin{array}{c}0.744 \\
(0.009)\end{array}$ & $\begin{array}{c}0.141 \\
(0.005)\end{array}$ & $\begin{array}{c}0.610 \\
(0.002)\end{array}$ & $\begin{array}{c}0.165 \\
(0.001)\end{array}$ & -6.443 & 1.18 & 6,051 \\
\hline Watches & $\begin{array}{c}0.804 \\
(0.012)\end{array}$ & $\begin{array}{c}0.101 \\
(0.006)\end{array}$ & $\begin{array}{c}0.398 \\
(0.006)\end{array}$ & $\begin{array}{c}0.250 \\
(0.009)\end{array}$ & -1.265 & 4.76 & 3,242 \\
\hline Toys & $\begin{array}{c}0.682 \\
(0.021)\end{array}$ & $\begin{array}{c}0.216 \\
(0.013)\end{array}$ & $\begin{array}{c}0.451 \\
(0.012)\end{array}$ & $\begin{array}{c}0.183 \\
(0.003)\end{array}$ & -3.102 & 1.47 & 1,269 \\
\hline Computers & $\begin{array}{c}0.795 \\
(0.009)\end{array}$ & $\begin{array}{c}0.212 \\
(0.006)\end{array}$ & $\begin{array}{c}0.721 \\
(0.008)\end{array}$ & $\begin{array}{c}0.160 \\
(0.003)\end{array}$ & -3.120 & 1.47 & 6,676 \\
\hline
\end{tabular}

NOTE: The dependent variable is log of deflated value-added. Standard errors are reported in parentheses. Labor is measured as number of full-time adjusted employees. All regressions include year dummies. $O L S$ is ordinary least square regression. $N P_{l m}$ is two-step estimation using a nonparametric labor demand function as proxy for productivity and controlling for imperfect competition. The estimated coefficients include elasticity, i.e., $\left(1+\frac{1}{\eta}\right) \beta_{l}$ for labor and $\left(1+\frac{1}{\eta}\right) \beta_{k}$ for capital. The $N P_{l m}$ specification includes previous year's the number of approved PBL over the population density in the productivity process (Section 4), current capital stock and previous labor are used as instruments and standard errors are computed using Ackerberg et al. (2011). Market output is measured as the market share weighted output in the municipality. Demand refers to the elasticity of substitution. Markup is defined as price over marginal cost. 


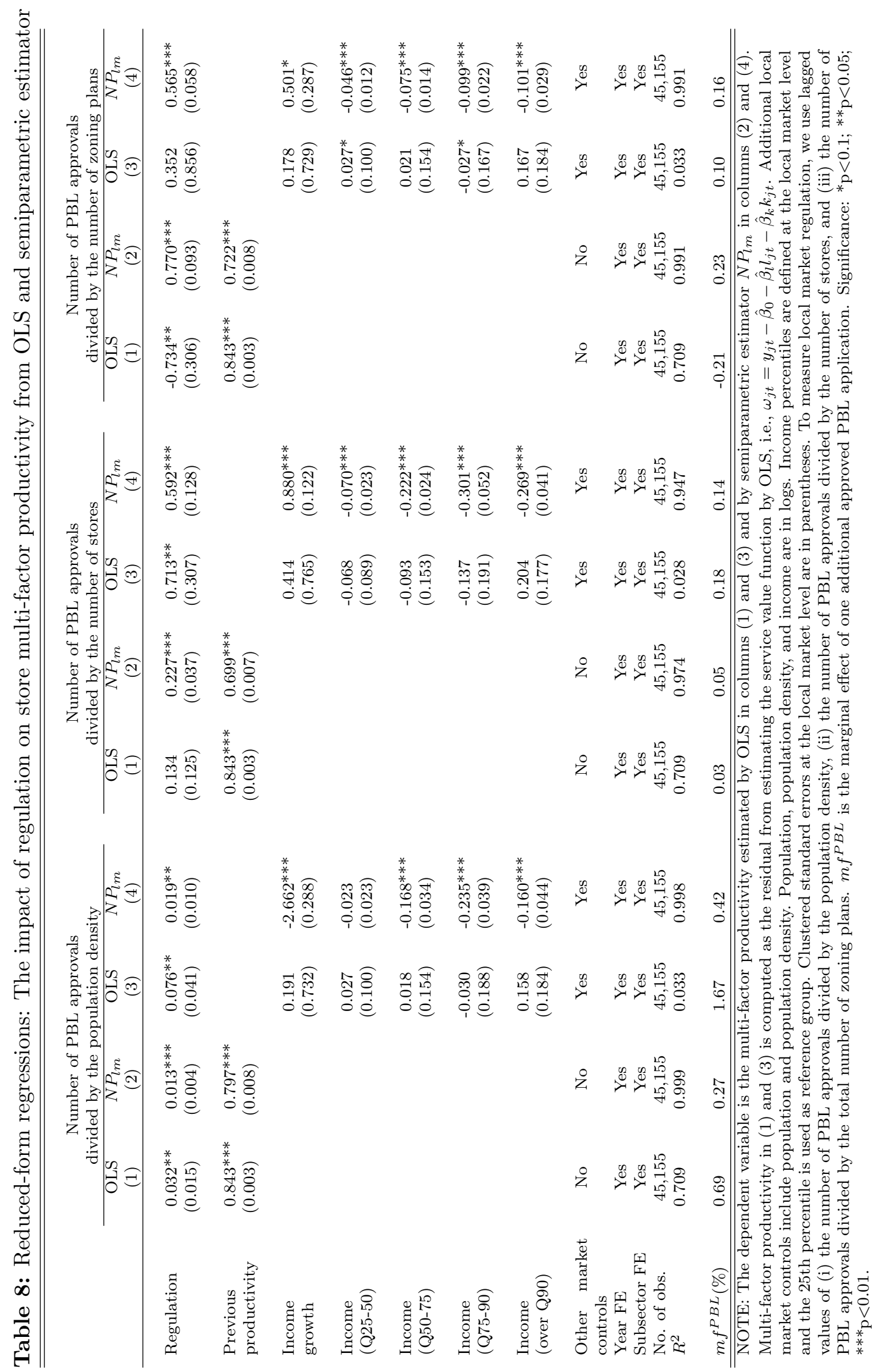


Table 9: The impact of regulation on store productivity using nonparametric estimation

\begin{tabular}{llllrrr}
\hline \hline Subsector & Mean & Std.dev. & Adj. $R^{2}$ & No. of obs. & \multicolumn{2}{c}{ Support } \\
\hline Textile & 3.25 & 3.88 & 0.402 & 1,079 & {$[-4.26$} & $9.08]$ \\
Clothing & 0.21 & 0.18 & 0.284 & 9,677 & {$[0.07$} & $0.72]$ \\
Footwear & 4.33 & 2.88 & 0.936 & 2,386 & {$[-0.18$} & $9.68]$ \\
Furniture & 0.94 & 1.19 & 0.610 & 6,336 & {$[-2.80$} & $1.78]$ \\
Electronics & 0.44 & 1.56 & 0.474 & 5,290 & {$[-1.03$} & $4.46]$ \\
Hardware & 0.37 & 0.18 & 0.347 & 5,597 & {$[-0.09$} & $0.56]$ \\
Books & 2.04 & 4.16 & 0.594 & 2,261 & {$[-3.77$} & $10.69]$ \\
Sports & 0.76 & 0.36 & 0.297 & 4,358 & {$[0.50$} & $1.79]$ \\
Watches & 0.72 & 6.34 & 0.644 & 2,468 & {$[-8.60$} & $12.71]$ \\
Toys & 4.39 & 1.41 & 0.457 & 899 & {$[3.51$} & $8.97]$ \\
Computers & 1.31 & 2.70 & 0.406 & 4,804 & {$[-1.71$} & $7.54]$ \\
\hline \hline
\end{tabular}

NOTE: This table shows means and standard deviations, across local markets and years, of the median marginal effect (\%) on stores' productivity when an additional PBL application is approved. The number of PBL approvals divided by the population density is used as a proxy for regulation (Section 2). Marginal effects are computed for individual stores using their observed values of previous productivity, the regulation measure and population density. The OLS estimator is used to estimate the controlled Markov process. The support is computed using 1,000 simulation draws from the estimated distribution of productivity.

Table 10: Percent changes in aggregate local market productivity from more liberal regulation

\begin{tabular}{lcllc}
\hline \hline & & & & \\
Subsector & 25th perc. & Median & 75 th perc. & Mean \\
\hline Textile & 0.39 & 2.35 & 3.13 & 5.23 \\
Clothing & 0.22 & 0.34 & 1.06 & 0.53 \\
Footwear & 3.23 & 5.67 & 5.89 & 7.66 \\
Furniture & 0.05 & 0.37 & 1.12 & 1.34 \\
Electronics & -0.45 & 0.00 & 3.55 & 0.47 \\
Hardware & 0.16 & 0.30 & 1.84 & 0.46 \\
Books & -0.78 & 1.27 & 1.53 & 3.69 \\
Sports & 0.48 & 0.64 & 0.72 & 0.90 \\
Watches & -2.71 & 0.60 & 1.02 & 3.85 \\
Toys & 3.47 & 4.39 & 3.80 & 5.26 \\
Computers & -0.63 & 0.18 & 0.19 & 0.90 \\
\hline \hline
\end{tabular}

NOTE: This table displays summary statistics for the percent changes in aggregate local market productivity from an additional PBL approval. The number of PBL approvals divided by the population density is used as a proxy for regulation (Section 2). The marginal effects are computed for individual stores using their observed values of previous productivity, the regulation measure and population density. Municipalities (290 in total) are used as local markets. Marginal effects for individual stores are used (Table 9) with output market shares as weights. 
Table 11: Aggregate impact of more liberal regulation by store and market size

\begin{tabular}{|c|c|c|c|c|c|c|}
\hline & \multicolumn{3}{|c|}{ Panel A: Median impact at the store level } & \multicolumn{3}{|c|}{ "Panel B: Median impact at the market level } \\
\hline & \multicolumn{2}{|c|}{ No. of employees } & \multirow{2}{*}{$\begin{array}{l}\text { Test } H_{0}: \\
\text { Equal medians }\end{array}$} & \multicolumn{2}{|c|}{ Population } & \multirow{2}{*}{$\begin{array}{l}\text { Test } H_{0}: \\
\text { Equal medians }\end{array}$} \\
\hline & $\begin{array}{c}\text { Below median } \\
(\%)\end{array}$ & $\begin{array}{c}\text { Above median } \\
(\%)\end{array}$ & & $\begin{array}{c}\text { Below median } \\
(\%)\end{array}$ & $\begin{array}{c}\text { Above median } \\
(\%)\end{array}$ & \\
\hline Textile & 4.22 & 2.88 & Reject & 3.25 & 1.75 & Reject \\
\hline Clothing & 0.19 & 0.23 & Reject & 0.35 & 0.27 & Reject \\
\hline Footwear & 5.41 & 4.77 & Reject & 6.03 & 4.37 & Reject \\
\hline Furniture & 1.03 & 0.93 & Reject & 0.99 & 0.41 & Reject \\
\hline Electronics & 1.13 & 0.13 & Reject & -0.11 & 0.01 & Accept \\
\hline Hardware & 0.42 & 0.36 & Reject & 0.41 & 0.22 & Reject \\
\hline Books & 2.59 & 1.03 & Reject & 2.91 & 0.09 & Reject \\
\hline Sports & 0.69 & 0.59 & Reject & 0.80 & 0.49 & Reject \\
\hline Watches & 1.60 & 0.51 & Reject & 2.10 & -0.32 & Reject \\
\hline Toys & 4.57 & 3.87 & Reject & 4.75 & 3.89 & Reject \\
\hline Computers & 1.56 & 0.85 & Reject & -0.06 & 0.24 & Reject \\
\hline
\end{tabular}

NOTE: The figures present the median values of the marginal effects by by store and year (Panel A) and by market and year (Panel B). Municipalities (290 in total) represent local markets. Stores are defined as small if the number of employees is below the median and large otherwise. Local markets are defined as small if the population is below the median and as large otherwise. The number of PBL approvals divided by the population density is used as a proxy for regulation (Section 2). Marginal effects measure the percent changes in store productivity (Panel A) and aggregate local market productivity (Panel B) from an additional PBL approval. Marginal effects are computed for individual stores using their observed values of previous productivity, the regulation measure and population density. The aggregate weighted productivity in local markets is computed by using the marginal effects in Table 9 and output market shares as weights. To test whether the medians are equal for small and large stores, we follow recent literature in statistics and use quantile regressions with a group indicator. 


\title{
ONLINE APPENDIX
}

\section{A Dynamic Analysis of Entry Regulations and Productivity in Retail Trade}

\author{
Florin Maican* and Matilda Orth ${ }^{\dagger}$ \\ December 7, 2014
}

The online appendix contains seven parts. Appendix A provides additional information about entry regulation in Sweden. Appendix B presents additional information about data sources. Appendix C provides additional reduced-form evidence of the effect of entry regulation on productivity. Appendix D discusses the identification, productivity measure and selection using the nonparametric approach. Appendix E discusses the identification and estimation of the model using a parametric approach. Appendix F discusses the estimation results using alternative measures of entry regulation and the nonparametric approach.

\section{Appendix A Entry regulation}

On July 1, 1987, a new regulation was imposed in Sweden, the Plan and Building Act ("Plan och Bygglagen", PBL). ${ }^{1}$ Compared to the previous legislation, the decision process was decentralized, giving local governments authority over entry in their municipalities,

\footnotetext{
${ }^{*}$ Research Institute of Industrial Economics (IFN) and University of Gothenburg, Box 640, SE-405 30, Göteborg, Sweden, Phone +46-31-786 4866, Fax +46-31-786 4154, E-mail: florin.maican@economics.gu.se

${ }^{\dagger}$ Research Institute of Industrial Economics (IFN), Box 55665, SE-102 15, Stockholm, Sweden, Phone +46-8-665 4531, Fax +46-8-665 4599, E-mail: matilda.orth@ifn.se

${ }^{1}$ The Swedish Competition Authority (2001:4) provides a detailed description.
} 
and citizens could now appeal these decisions. Since 1987, only minor changes have been implemented in the PBL. From April 1, 1992 to January 1, 1997, the regulation was slightly different, making it explicit that the use of buildings should not hamper efficient competition. Since 1997, the PBL has been essentially the same as it was prior to 1992. Long time lags in the planning process make it impossible to directly evaluate the impact of decisions. In practice, differences due to the policy change seem small (Swedish Competition Authority, 2001:4). The PBL is argued to be one of a major barrier to entry, resulting in different outcomes, e.g., price levels across municipalities. Municipalities are then, through the regulation, able to affect prices. In detail, the Swedish Competition Authority finds that the number of square meters of sales space per capita is lower in municipalities that constrain entry, while municipalities with a higher market shares occupied by large and discount stores have lower prices (Swedish Competition Authority, 2001:4; Swedish Competition Authority, 2004:2).

Political seats. We access data on the share of seats to each political party in local municipal governments. The Social Democratic Party is the largest party nationally, with 40.6 percent of seats on average, and it collaborates with the Left Party (8 percent) and the Green Party (4.2 percent). The non-socialist group consists of the Moderate Party (18 percent), and it is most often aligned with the Center Party (13.2 percent), the Christian Democratic Party (5.9 percent), and the Liberal Party (5.6 percent). The Center Party is traditionally strong in rural areas. For our purposes, therefore, we only consider the Moderate Party, the Liberal Party and Christian Democrats in the non-socialist group. Twenty-two per cent of municipalities had a non-socialist majority during 1996-1998, increasing to 32 percent during 1999-2002. The non-socialists had 8.6-85 percent support, with an average of 40.7 percent in 1996-1998 and 44.1 percent in 1999-2002.

How local governments implement the PBL depends on the preferences of the politicians (Bertrand and Kramarz, 2002; Schivardi and Viviano, 2011). In Sweden, the expectation is that non-socialist local governments will apply the PBL more liberally. ${ }^{2}$

\footnotetext{
${ }^{2}$ This is contrary to, for instance, France and Italy. It is well established that the Swedish nonsocialist government is more positive to liberalization. The non-socialist government has deregulated the
} 
The exogeneity of political preferences for measuring regulatory stringency relies on local economic issues' not determining future election outcomes. In Sweden, we believe it is reasonable to rely on the idea that land use issues do not turn local elections around. Swedish municipalities have many responsibilities. Child care, schooling and elderly care are main spending areas that are likely to influence voter's decisions more heavily.

Municipalities with a non-socialist majority approved more applications. The correlation between the share of non-socialist seats and the number of approved applications is 0.45. The corresponding correlation for the share (rather than the number) of approved applications is 0.25 .

\section{Appendix B The FS-RAMS data}

FS-RAMS contains all stores, based on organization number, in different Swedish industries from 1996 to 2002. Value added is defined as total shipments, adjusted for inventory changes, minus the cost of materials. Labor is the full-time adjusted average number of employees during the year. We deflated sales, value-added, wages, and investment by the subsector price indexes or the consumer price index (CPI).

Capital is constructed using a perpetual inventory method, $K_{t+1}=(1-\delta) K_{t}+I_{t}$. Because the data distinguish between buildings and equipment, all calculations of the capital stock are performed separately for buildings and equipment. In the paper, we include equipment in the capital stock. However, including both equipment and buildings in the capital stock does not change our results. As suggested by Hulten and Wykoff (1981), buildings are depreciated at a rate of 0.0361 and equipment by 0.1179 . To construct capital series using the perpetual inventory method, an initial capital stock is needed. We set initial capital stock to the first available observation in FS-RAMS, defining entry as the first year a store has data in FS (some of the stores have been in FS since 1973). Retail subsectors (SNI codes) We take all stores that belong to SNI code 52 (Retail pharmacy and telecom markets, for example. 
trade, except motor vehicles and motorcycles; repair of personal household goods), and exclude monopolies and food, SNI 52111-52129 - Retail sales in non-specialized stores where food, beverages, or tobacco are predominant;

SNI 52250 - Retail sales of alcoholic and other beverages; SNI 52210-52242, 5227152279, 52330 - Retail sales of food and beverages in specialized stores; SNI 52260 Retail sales of tobacco in specialized stores; SNI 52310 and 52320 - Dispensing chemists and Retail sales of medical and orthopedic goods; SNI 52488, 52491-52499, 52501-52509, 52710-52740 - Retail sales in specialized stores, including spectacles and other optical goods, photographic equipment and related services, flowers and other plants, pet animals, second-hand goods, art, art gallery activities, coins and stamps, computers, office machinery and computer software, telecommunication equipment, wallpaper, carpets, rugs and floor coverings, boats and boating accessories, office furniture, specialized stores n.e.c.; SNI 5261 - Retail sales vial mail.order houses; SNI 5262 and 5263 - Retail sales via stalls, markets and other non-store retail sales, and other stores.

SNI "Textiles" Retail sales of textiles (52410); "Clothing" Retail sales of clothing (52421-52425); "Footwear" Retail sales of footwear and leather goods" (52431-52432); "Furniture" Retail sales of furniture, lighting equipment, and household articles n.e.c. (52441-52444); "Electronics" Retail sales of electrical household appliances and radio and television goods (52451-52454); "Hardware" Retail sales of hardware, paints and glass (52461-52462); "Books" Retail sales of books, newspapers and stationery (5247152472); "Watches" Retail sales of watches and clocks, jewelery, gold wares, and silverware (52483-52484); "Sports" Retail sales of sports and leisure goods (52485); "Toys" Retail sales of games and toys (52486); "Computers" Retail sales of computers, software and telecommunications equipment (52493-52494).

Descriptive statistics. Table B.1 presents median and dispersion measures for the key variables from 1996 to 2002. Dispersion is defined as the difference between the 75th and 25th percentiles of stores divided by the median. This measure, which indicates the spread of the distribution, is selected to avoid measurement problems and outliers. The 
median store increases sales by 26 percent over the period. The corresponding increase in value-added is 31 percent, while investments increase 19 percent. The median store has three employees (full-time adjusted) over the entire period, most likely because stores that change size are located in the tails of the distribution. For all variables, dispersion increases over time. A comparison across variables shows that investment has the highest values, i.e., investment is the variable that differs the most across stores. The level of dispersion is approximately three times larger than those for investment than for sales, value-added, and the number of employees.

Table B.2 reports descriptive statistics of annual store-level growth in terms of valueadded, number of employees, wages, and capital over the study period. The share of small stores in each subsector is highest in textiles but lowest in hardware. The mean value-added increases the most in sports and toys but the least in textiles, footwear, and books. Employment growth is highest in toys and small sport stores but lowest in electronics and watches. Capital growth is high in electronics, and sports but low in textiles and watches. The mean values are also high for furniture, whereas low corresponding values are found for books and toys.

Table B.1: Median and dispersion, Swedish retail trade 1996-2002

\begin{tabular}{|c|c|c|c|c|c|c|c|c|}
\hline & \multicolumn{2}{|c|}{ Sales } & \multicolumn{2}{|c|}{ Value-added } & \multicolumn{2}{|c|}{ Investment } & \multicolumn{2}{|c|}{ Labor } \\
\hline & Median & Dispersion & Median & Dispersion & Median & Dispersion & Median & Dispersion \\
\hline 1996 & 2,855 & 1.77 & 628 & 1.58 & 13.0 & 4.92 & 3 & 1.33 \\
\hline 1997 & 2,854 & 1.83 & 633 & 1.70 & 15.7 & 4.44 & 3 & 1.33 \\
\hline 1998 & 3,086 & 1.80 & 696 & 1.68 & 15.5 & 4.25 & 3 & 1.00 \\
\hline 1999 & 3,254 & 1.84 & 744 & 1.69 & 17.4 & 4.33 & 3 & 1.00 \\
\hline 2000 & 3,453 & 1.84 & 783 & 1.71 & 19.1 & 4.55 & 3 & 1.00 \\
\hline 2001 & 3,466 & 1.85 & 789 & 1.73 & 16.7 & 4.44 & 3 & 1.00 \\
\hline 2002 & 3,607 & 1.88 & 824 & 1.77 & 15.5 & 4.59 & 3 & 1.00 \\
\hline
\end{tabular}


Table B.2: Store level growth by subsector 1996-2002

\begin{tabular}{|c|c|c|c|c|c|c|c|c|c|c|}
\hline & \multirow{2}{*}{\multicolumn{2}{|c|}{ Value-added }} & \multicolumn{2}{|c|}{ Employees } & \multicolumn{2}{|c|}{ Capital } & \multicolumn{2}{|c|}{ Wages } & \multirow{2}{*}{$\begin{array}{l}\text { Share } \\
\text { small }\end{array}$} & \multirow{2}{*}{$\begin{array}{l}\text { No. of } \\
\text { stores }\end{array}$} \\
\hline & & All & Small & All & Small & All & Small & All & & \\
\hline \multirow[t]{2}{*}{ Textiles } & 0.046 & 0.056 & 0.037 & 0.044 & 0.109 & 0.120 & 0.051 & 0.059 & 0.893 & 355 \\
\hline & $(0.275)$ & $(0.274)$ & $(0.329)$ & $(0.316)$ & $(0.423)$ & $(0.421)$ & $(0.284)$ & $(0.270)$ & $(0.012)$ & (41) \\
\hline \multirow[t]{2}{*}{ Clothing } & 0.087 & 0.089 & 0.045 & 0.060 & 0.163 & 0.176 & 0.059 & 0.073 & 0.772 & 2,467 \\
\hline & $(0.340)$ & $(0.318)$ & $(0.336)$ & $(0.318)$ & $(0.507)$ & $(0.495)$ & $(0.279)$ & $(0.254)$ & $(0.022)$ & (72) \\
\hline \multirow[t]{2}{*}{ Footwear } & 0.050 & 0.054 & 0.029 & 0.040 & 0.127 & 0.150 & 0.037 & 0.049 & 0.777 & 591 \\
\hline & $(0.246)$ & $(0.228)$ & $(0.314)$ & $(0.294)$ & $(0.436)$ & $(0.459)$ & $(0.235)$ & $(0.210)$ & $(0.008)$ & (41) \\
\hline \multirow[t]{2}{*}{ Furniture } & 0.102 & 0.098 & 0.045 & 0.063 & 0.198 & 0.222 & 0.069 & 0.080 & 0.748 & 1,603 \\
\hline & $(0.337)$ & $(0.300)$ & $(0.330)$ & $(0.309)$ & $(0.544)$ & $(0.549)$ & $(0.278)$ & $(0.239)$ & $(0.019)$ & (23) \\
\hline \multirow[t]{2}{*}{ Electronics } & 0.064 & 0.069 & 0.036 & 0.032 & 0.193 & 0.201 & 0.048 & 0.061 & 0.793 & 1,291 \\
\hline & $(0.274)$ & $(0.260)$ & $(0.291)$ & $(0.190)$ & $(0.477)$ & $(0.458)$ & $(0.223)$ & $(0.206)$ & (0.019) & $(62)$ \\
\hline \multirow[t]{2}{*}{ Hardware } & 0.076 & 0.073 & 0.032 & 0.034 & 0.185 & 0.185 & 0.051 & 0.061 & 0.686 & 1,313 \\
\hline & $(0.284)$ & $(0.243)$ & $(0.302)$ & $(0.188)$ & $(0.441)$ & $(0.402)$ & $(0.245)$ & $(0.200)$ & $(0.010)$ & $(22)$ \\
\hline \multirow[t]{2}{*}{ Books } & 0.052 & 0.051 & 0.024 & 0.044 & 0.129 & 0.136 & 0.039 & 0.051 & 0.716 & 561 \\
\hline & $(0.255)$ & $(0.218)$ & $(0.323)$ & $(0.297)$ & $(0.412)$ & $(0.397)$ & $(0.256)$ & $(0.214)$ & $(0.027)$ & (50) \\
\hline \multirow[t]{2}{*}{ Sports } & 0.100 & 0.106 & 0.060 & 0.075 & 0.186 & 0.197 & 0.079 & 0.091 & 0.798 & 1,101 \\
\hline & (0.333) & $(0.312)$ & $(0.347)$ & $(0.331)$ & $(0.450)$ & $(0.451)$ & $(0.293)$ & $(0.268)$ & $(0.021)$ & (10) \\
\hline \multirow[t]{2}{*}{ Watches } & 0.031 & 0.036 & 0.031 & 0.024 & 0.107 & 0.132 & 0.033 & 0.043 & 0.829 & 594 \\
\hline & $(0.208)$ & $(0.202)$ & $(0.299)$ & $(0.198)$ & (0.393) & $(0.418)$ & $(0.211)$ & $(0.196)$ & (0.013) & (26) \\
\hline \multirow[t]{2}{*}{ Toys } & 0.097 & 0.104 & 0.061 & 0.082 & 0.153 & 0.155 & 0.064 & 0.084 & 0.698 & 228 \\
\hline & $(0.351)$ & $(0.320)$ & $(0.359)$ & $(0.336)$ & $(0.433)$ & $(0.427)$ & $(0.302)$ & $(0.271)$ & (0.036) & (13) \\
\hline \multirow[t]{2}{*}{ Computers } & 0.196 & 0.212 & 0.042 & 0.080 & 0.211 & 0.221 & 0.162 & 0.186 & 0.754 & 1,176 \\
\hline & $(0.377)$ & $(0.356)$ & $(0.307)$ & $(0.273)$ & $(0.490)$ & $(0.474)$ & $(0.303)$ & $(0.279)$ & $(0.018)$ & (26) \\
\hline
\end{tabular}

NOTE: The figures presents mean (standard deviation) of store level growth by subsector and year during the period 19962002. Stores are defined as small if the number of employees is below the median and large otherwise. Share small is the number of small stores over the total number of stores in the subsector. Value added, capital and wages are measured in thousands of 1996 SEK (1USD=6.71SEK, 1EUR=8.63 SEK). 


\section{Appendix C Additional reduced-form evidence of the effect of entry regulation on productiv- ity}

Regulation and productivity. To document the empirical relationship between the degree of regulatory stringency and productivity, we regress multi-factor productivity estimated by OLS and labor productivity on different entry regulation variables. Results without local market controls and subsector fixed effects that complement the findings in Section 3 in the paper are presented in Table C.1. These results also show that a more liberal entry regulation has a positive and statistically significant effect on productivity. Regulation index and labor productivity. To document the empirical relationship between the regulation index presented in Section 2 and productivity, we regress labor productivity on the regulation index using different weights. We pool all stores from all subsectors, use each store's value-added per full-time adjusted employee to measure labor productivity and use three different proxies for local market regulation. Table C.2 shows that the coefficient on the regulation is positive for all specifications, and statistically significant for a majority of the specifications. This shows additional evidence that there is a link between regulation and productivity. 
Table C.1: Reduced-form regressions: The impact of regulation on store multi-factor productivity and labor productivity

\begin{tabular}{|c|c|c|c|c|c|c|}
\hline & \multicolumn{2}{|c|}{$\begin{array}{l}\text { Number of PBL } \\
\text { approvals divided } \\
\text { population density }\end{array}$} & \multicolumn{2}{|c|}{$\begin{array}{l}\text { Number of PBL } \\
\text { approvals divided by } \\
\text { number of stores }\end{array}$} & \multicolumn{2}{|c|}{$\begin{array}{c}\text { Number of PBL } \\
\text { approvals divided by } \\
\text { number of zoning plans }\end{array}$} \\
\hline & $\begin{array}{c}\text { OLS } \\
(1)\end{array}$ & $\begin{array}{c}\text { Labor } \\
(2)\end{array}$ & $\begin{array}{l}\text { OLS } \\
(1) \\
\end{array}$ & $\begin{array}{c}\text { Labor } \\
(2)\end{array}$ & $\begin{array}{l}\text { OLS } \\
(1)\end{array}$ & $\begin{array}{c}\text { Labor } \\
(2)\end{array}$ \\
\hline Regulation & $\begin{array}{c}0.078^{*} \\
(0.041)\end{array}$ & $\begin{array}{l}0.017^{* * *} \\
(0.004)\end{array}$ & $\begin{array}{c}0.754^{*} \\
(0.446)\end{array}$ & $\begin{array}{c}0.098^{*} \\
(0.050)\end{array}$ & $\begin{array}{c}0.584 \\
(0.858)\end{array}$ & $\begin{array}{c}0.223^{* *} \\
(0.098)\end{array}$ \\
\hline Other market controls & No & No & No & No & No & No \\
\hline Year FE & Yes & Yes & Yes & Yes & Yes & Yes \\
\hline Subsector FE & No & No & No & No & No & No \\
\hline No. of obs. & 45,155 & 45,155 & 45,155 & 45,155 & 45,155 & 45,155 \\
\hline$R^{2}$ & 0.009 & 0.090 & 0.005 & 0.090 & 0.009 & 0.090 \\
\hline
\end{tabular}

NOTE: The dependent variable is multi-factor productivity in column (1) and labor productivity in column (2). Multi-factor productivity is computed as the residual from estimating the service value function by OLS, i.e, $\omega_{j t}=y_{j t}-\hat{\beta}_{0}-\hat{\beta}_{l} l_{j t}-\hat{\beta}_{k} k_{j t}$. Labor productivity is measured as log of value-added per total number of employees. Clustered standard errors at the local market level are presented in parentheses. To measure local market regulation, we use lagged values of (i) the number of PBL approvals divided by the population density, (ii) the number of PBL approvals divided by the number of stores, and (iii) the number of PBL approvals divided by the total number of zoning plans. Income percentiles are defined at the local market level. Significance: ${ }^{*} \mathrm{p}<0.1 ;{ }^{* *} \mathrm{p}<0.05 ;{ }^{* * *} \mathrm{p}<0.01$ 
Table C.2: Reduced-form regressions: The impact of regulation on store labor productivity

\begin{tabular}{lcccccc}
\hline \hline & & & & & & \\
Model specification & $(1)$ & $(2)$ & $(3)$ & $(4)$ & $(5)$ & $(6)$ \\
\hline Regulation index & 0.0273 & 0.0377 & 0.0018 & 0.0042 & 0.0004 & 0.0040 \\
& $(0.0120)$ & $(0.0121)$ & $(0.0027)$ & $(0.0028)$ & $(0.0025)$ & $(0.0025)$ \\
Log of population & 0.0163 & 0.0098 & 0.0205 & 0.0159 & 0.0203 & 0.0161 \\
& $(0.0030)$ & $(0.0031)$ & $(0.0026)$ & $(0.0026)$ & $(0.0026)$ & $(0.0026)$ \\
Log of population density & 0.0013 & 0.0133 & -0.0035 & 0.0059 & -0.0031 & 0.0060 \\
& $(0.0028)$ & $(0.0029)$ & $(0.0021)$ & $(0.0022)$ & $(0.0021)$ & $(0.0022)$ \\
Log of income & 0.3298 & 0.1319 & 0.3292 & 0.1275 & 0.3344 & 0.1291 \\
& $(0.0170)$ & $(0.0233)$ & $(0.0194)$ & $(0.0255)$ & $(0.0185)$ & $(0.0249)$ \\
$R^{2}$ & 0.0117 & 0.0147 & 0.0117 & 0.0146 & 0.0117 & 0.0146 \\
Year fixed effect & No & Yes & No & Yes & No & Yes \\
No. of obs. & 69,526 & 69,526 & 69,526 & 69,526 & 69,526 & 69,526 \\
\hline \hline
\end{tabular}

NOTE: Standard errors are in parentheses. Labor productivity is measured as log of value-added per total number of employees. To measure local market regulation, (1)-(2) use number of PBL approvals divided by the population density; (3)-(4) use the index: $0.5^{*}$ (share of liberal seats) $+0.25^{*}$ (number of PBL approvals/number of stores) $+0.25^{*}$ (number of PBL approvals/number of zoning plans); and (5)-(6) use the index: $0.33^{*}$ (share of liberal seats) +0.33 (number of PBL approvals/number of stores) $+0.33^{*}$ (number of PBL approvals/number of zoning plans). 


\section{Appendix D Identification and productivity measure}

The identification and interpretation of the results depend on the assumption regarding the remaining demand shocks $u_{j t}^{d}$. If $u_{j t}^{d}$ are i.i.d. shocks, not predicted or anticipated by stores when they make input and exit decisions, we can identify technical productivity $\omega_{j t}$ separately from demand. If $u_{j t}^{d}$ are correlated demand shocks, we need additional assumptions for identification because the scalar unobservable assumption in OP is violated. In retail trade, regulation might have a lagged effect on both prices and productivity, for example. If $\omega_{j t}$ and $u_{j t}^{d}$ follow independent Markov processes, the demand shock will determine the optimal choices of labor and/or investment through which it affects productivity. We can then identify quality-adjusted productivity, i.e., the sum of technical productivity and remaining demand shocks $\left(\omega_{j t}-\frac{1}{1+\eta_{s}} u_{j t}^{d}\right){ }^{3} \quad$ An important difference between technical productivity and quality-adjusted productivity is the interpretation of the results.

Selection. To account for large retail stores being more likely to survive larger shocks to productivity than small stores, we can control for selection. The decision to exit is correlated with $v_{j t}$ because it relies on current productivity. We can control for selection by estimating survival probabilities as

$$
\begin{aligned}
\operatorname{Pr}\left(\chi_{t}=1 \mid \underline{\omega}_{t}\left(k_{j t}, \mathbf{z}_{m t-1}\right), \boldsymbol{F}_{t-1}\right)= & \operatorname{Pr}\left(\omega_{t} \geq \underline{\omega}_{t}\left(k_{j t}, \mathbf{z}_{m t-1}\right) \mid \underline{\omega}_{t}\left(k_{j t},\right.\right. \\
& \left.\left.\mathbf{z}_{m t-1}\right), \omega_{j t-1}\right) \\
= & P_{t-1}\left(l_{j t-1}, k_{j t-1}, w_{j t-1}, p_{s t-1},\right. \\
& \left.q_{s m t-1}, \mathbf{z}_{m t-1}\right) \equiv \mathscr{P}_{j t-1},
\end{aligned}
$$

where the threshold market productivity $\underline{\omega}_{t}$ and the information set $\boldsymbol{F}_{t-1}$ will enter the function $g(\cdot)$, and regulation $r_{m t-1}$ is included in $\mathbf{z}_{m t-1}$. As a result, threshold market productivity can be expressed as a function of $\mathscr{P}_{t-1}$ and $\boldsymbol{F}_{t-1}$. Therefore, the controlled

\footnotetext{
${ }^{3}$ If $\omega_{j t}$ and $u_{j t}^{d}$ follow dependent Markov processes, the demand shock will enter the information set that forms expected productivity $E\left[\omega_{j t} \mid \omega_{j t-1}, r_{m t-1}, u_{j t-1}^{d}\right]$. We can use an estimate of $u_{j t}^{d}$ in line with Berry, Levinsohn, and Pakes (1995), but this is not feasible due to data limitations (we would need additional store specific information).
} 
Markov process becomes $g\left(\omega_{j t-1}, r_{m t-1}, \mathscr{P}_{j t-1}\right)$.

\section{Appendix E Parametric approach}

Under the assumptions of Cobb-Douglas technology and that labor is a static and variable input, the labor function from the stores' short-run optimization problem takes the form (Doraszelski and Jaumandreu, 2013)

$$
l_{j t}=\frac{1}{1-\beta_{l}}\left[\ln \left(\beta_{l}\right)+\beta_{k} k_{j t}+\omega_{j t}-\left(w_{j t}-p_{j t}\right)+\ln \left(1+\frac{1}{\eta_{s}}\right)\right] .
$$

Solving for $\omega_{j t}$ yields the inverse labor demand function

$$
\begin{aligned}
\omega_{j t}= & \frac{\eta_{s}}{1+\eta_{s}}\left[\lambda_{0}+\left[\left(1-\beta_{l}\right)-\frac{1}{\eta_{s}} \beta_{l}\right] l_{j t}+w_{j t}-p_{s t}-\left(1+\frac{1}{\eta_{s}}\right) \beta_{k} k_{j t}\right. \\
& \left.+\frac{1}{\eta_{s}} q_{s m t}+\frac{1}{\eta_{s}} \mathbf{z}_{m t}^{\prime} \boldsymbol{\beta}_{z}\right],
\end{aligned}
$$

where $p_{s t}$ is used as a proxy for $p_{s m t}$ and $\lambda_{0}=-\ln \left(\beta_{l}\right)-\ln \left(1+1 / \eta_{s}\right)-\ln E\left[\exp \left(\xi_{j t}\right)\right]+$ $\frac{1}{\eta_{s}} \ln E\left[\exp \left(\varepsilon_{j t}\right)\right] .{ }^{4}$ The labor demand function (E-2), with $\omega_{j t}=g\left(\omega_{j t-1}, r_{m t-1}\right)+v_{j t}$, and the final value-added generating function, i.e.,

$$
\begin{aligned}
y_{j t}= & \left(1+\frac{1}{\eta_{s}}\right)\left[\beta_{l} l_{j t}+\beta_{k} k_{j t}\right]-\frac{1}{\eta_{s}} q_{s m t}-\frac{1}{\eta_{s}} \mathbf{z}_{m t}^{\prime} \boldsymbol{\beta}_{z}+\left(1+\frac{1}{\eta_{s}}\right) g\left(\omega_{j t-1}, r_{m t-1}\right) \\
& +\left(1+\frac{1}{\eta_{s}}\right) v_{j t}-\frac{1}{\eta_{s}} u_{j t}^{d}+\left(1+\frac{1}{\eta_{s}}\right) \xi_{j t}
\end{aligned}
$$

form a system of equations with $y_{j t}$ and $l_{j t}$ as endogenous variables.

Estimation. The estimation of our semi-parametric model adjusted for retailers (EOP) proceeds as follows. We first use a probit model with a third-order polynomial to estimate survival probabilities and then substitute the predicted survival probabilities into productivity process equation. We use the sieve minimum distance (SMD) procedure proposed by Newey and Powell (2003) and Ai and Chen (2003) for independent and identically

${ }^{4}$ The condition for identification is that the variables in the parametric section of the model are not perfectly predictable (in the least squares sense) on the basis of the variables in the non-parametric section (Robinson, 1988). Therefore there cannot be a functional relationship between the variables in the parametric and non-parametric sections (Newey, Powell, and Vella, 1999). 
distributed (i.i.d.) data. The goal is to obtain an estimable expression for the unknown parameters $\boldsymbol{\beta}$ and $g_{K_{T}}$, where $K_{T}$ indicates all parameters in $g(\cdot)$. We approximate $g(\cdot)$ by a third-order polynomial expansion in $\mathscr{P}_{t-1}, \omega_{j t-1}$ (given by $(\mathrm{E}-3)$ ) and $r_{m t-1} \cdot{ }^{5}$ We use a tensor product polynomial series of labor $\left(l_{j t-1}\right)$, capital $\left(k_{j t-1}\right)$, wages $\left(w_{j t-1}\right)$, the consumer price index in the subsector $\left(p_{s t}\right)$ and local market conditions $\left(\mathbf{z}_{m t-1}\right)$ as instruments, where the local market conditions include population, population density, and income. The same set of instruments is used to estimate the optimal weighting matrix. As there are nonlinearities in the coefficients, we use the Nelder-Mead numerical optimization method to minimize the GMM objective function

$$
\min _{\boldsymbol{\beta}, g_{K_{T}}} Q_{N}=\left[\frac{1}{N} W^{\prime} \rho(\boldsymbol{\beta})\right]^{\prime} A\left[\frac{1}{N} W^{\prime} \rho(\boldsymbol{\beta})\right],
$$

where $\rho(\boldsymbol{\beta})=\left(\left(1+\frac{1}{\eta_{s}}\right) v_{j t}-\frac{1}{\eta_{s}} u_{j t}^{d}+\left(1+\frac{1}{\eta_{s}}\right) \xi_{j t}\right)(\boldsymbol{\beta}), A$ is the weighting matrix defined as $A=\left[\frac{1}{N} W^{\prime} \rho(\boldsymbol{\beta}) \rho^{\prime}(\boldsymbol{\beta}) W\right]^{-1}$ and $W$ is the matrix of instruments. Using the specified GMM implementation, the parameter values $\left(\boldsymbol{\beta}, g_{K_{T}}\right)$ are jointly estimated. We control for local market characteristics in all estimations.

The semi-parametric regression is estimated using the sieve minimum distance (SMD) procedure proposed in Newey and Powell (2003) and Ai and Chen (2003) for independent and identically distributed (i.i.d.) data. ${ }^{6}$ The goal is to obtain an estimable expression for the unknown parameter of interest, $\boldsymbol{\alpha}=(\boldsymbol{\beta}, g)^{\prime}$. We denote the true value of the parameters with the subscript "a": $\boldsymbol{\alpha}_{a}=\left(\boldsymbol{\beta}_{a}, g_{a}\right)^{\prime}$. The moment conditions could then be written more compactly as

$$
E\left[\rho_{j}\left(\boldsymbol{x}_{t}, \boldsymbol{\beta}_{a}, g_{a}\right) \mid \boldsymbol{F}_{t}^{*}\right]=0, \quad j=1, \cdots, N
$$

\footnotetext{
${ }^{5}$ For robustness, we also expand $g(\cdot)$ using a fourth-order polynomial, but the results are similar.

${ }^{6}$ Chen and Ludvigson (2007) show that the SMD procedure and its large sample properties can be extended to stationary ergotic time series data.
} 
where $N$ is the total number of stores, $\boldsymbol{F}_{t}^{*}$ is the information set at time $t$, and $\rho_{j}(\cdot)$ is defined as

$$
\begin{aligned}
\rho_{j}\left(\boldsymbol{x}_{t}, \boldsymbol{\beta}_{a}, g_{a}\right) \equiv & y_{j t}-\left(1+\frac{1}{\eta_{s}}\right)\left[\beta_{0}+\beta_{l} l_{j t}+\beta_{k} k_{j t}\right]+\frac{1}{\eta_{s}} q_{m t}+\frac{1}{\eta_{s}} \mathbf{z}_{m t}^{\prime} \beta_{z} \\
& -g\left(\omega_{j t-1}, r_{m t-1}, \mathcal{P}_{j t-1}\right) .
\end{aligned}
$$

Let $\boldsymbol{F}_{t}$ be an observable subset of $\boldsymbol{F}_{t}^{*}$, then equation (E-6) implies

$$
E\left[\rho_{j}\left(\boldsymbol{x}_{t}, \boldsymbol{\beta}_{a}, g_{a}\right) \mid \boldsymbol{F}_{t}\right]=0 \quad j=1, \cdots, N .
$$

If the information set $\boldsymbol{F}_{t}$ is sufficiently informative, such that $E\left[\rho_{j}\left(\boldsymbol{x}_{t}, \boldsymbol{\beta}, g\right) \mid \boldsymbol{F}_{t}\right]=0$ for all $j$ and for any $0 \leq \beta<1$, then $(\boldsymbol{\beta}, g)^{\prime}=\left(\boldsymbol{\beta}_{a}, g_{a}\right)^{\prime}$. The true parameter values must satisfy the minimum distance criterion

$$
\boldsymbol{\alpha}_{a}=\left(\boldsymbol{\beta}_{a}, g_{a}\right)^{\prime}=\arg \min _{\boldsymbol{\alpha}} E\left[m\left(\boldsymbol{F}_{t}, \boldsymbol{\alpha}\right)^{\prime} m\left(\boldsymbol{F}_{t}, \boldsymbol{\alpha}\right)\right]
$$

where $m\left(\boldsymbol{F}_{t}, \boldsymbol{\alpha}\right)=E\left[\rho\left(\boldsymbol{x}_{t}, \boldsymbol{\alpha}\right) \mid \boldsymbol{F}_{t}\right], \rho\left(\boldsymbol{x}_{t}, \boldsymbol{\alpha}\right)=\left(\rho_{1}\left(\boldsymbol{x}_{t}, \boldsymbol{\alpha}\right), \cdots, \rho_{N}\left(\boldsymbol{x}_{t}, \boldsymbol{\alpha}\right)\right)^{\prime}$ for any candidate values $\boldsymbol{\alpha}=(\boldsymbol{\beta}, g)^{\prime}$. The moment conditions are used to describe the SMD estimation of $\boldsymbol{\alpha}_{a}=\left(\boldsymbol{\beta}_{a}, g_{a}\right)^{\prime}$. The SMD procedure has three parts. First, we can estimate the function $g(\cdot)$, which has an infinite dimension of unknown parameters, by a sequence of finite-dimensional unknown parameters (sieves) denoted $g_{K_{T}}$. The approximation error decreases as the dimension $K_{T}$ increases with sample size $N$. Second, the unknown conditional mean $m\left(\boldsymbol{F}_{t}, \boldsymbol{\alpha}\right)=E\left[\rho\left(\boldsymbol{x}_{t}, \boldsymbol{\alpha}\right) \mid \boldsymbol{F}_{t}\right]$ is replaced with a consistent nonparametric estimator $\hat{m}\left(\boldsymbol{F}_{t}, \boldsymbol{\alpha}\right)$ for any candidate parameter values $\boldsymbol{\alpha}=(\boldsymbol{\beta}, g)^{\prime}$. Finally, the function $g_{K_{T}}$ is estimated jointly with the finite dimensional parameters $\boldsymbol{\beta}$ by minimizing a quadratic norm of estimated expectation functions:

$$
\hat{\boldsymbol{\alpha}}=\arg \min _{\boldsymbol{\beta}, g_{K_{T}}} \frac{1}{T} \sum_{t=1}^{T} \hat{m}\left(\boldsymbol{F}_{t}, \boldsymbol{\beta}, g_{K_{T}}\right)^{\prime} \hat{m}\left(\boldsymbol{F}_{t}, \boldsymbol{\beta}, g_{K_{T}}\right) .
$$


We approximate $g(\cdot)$ by a third-order polynomial and substitute it into (E-7) as if it were the true model. As the errors $\rho_{j}(\cdot)$ are orthogonal to the regressors $\boldsymbol{F}_{t}=$ $\left(1, l_{t-1}, k_{t}, r_{t-1}, \mathbf{z}_{t-1}\right)$, we use a third-order power series of $\boldsymbol{F}_{t}$, denoted $\boldsymbol{P}$, as instruments. We estimate $m(\boldsymbol{F}, \boldsymbol{\alpha})$ as the predicted values from regressing the errors $\rho_{j}(\cdot)$ on the instruments. Using $\boldsymbol{P}$, we specify the weighting matrix as $\boldsymbol{W}=I_{N} \otimes\left(\boldsymbol{P}^{\prime} \boldsymbol{P}\right)^{-1}$, making the estimation a GMM case. The weighting matrix $\boldsymbol{W}$ places greater weight on moments that are highly correlated with the instruments. Using the specified GMM implementation, the parameter values $\left(\boldsymbol{\beta}, g_{K_{T}}\right)$ are jointly estimated. The results from parametric approach are available from authors.

\section{Appendix F Alternative measures of entry regula- tion using the nonparametric approach}

This appendix discusses the findings using the number of alternative proxies for regulation measure.

\section{Appendix F.1 Number of PBL approvals divided by the num- ber of stores and number of PBL approvals di- vided by the number of zoning plans}

Service production function estimates. Table F.1 shows the service production function estimates using the semiparametric $N P_{l m}$ estimator and two alternative proxies for the regulation measures, i.e., (1) the number of PBL approvals divided by the total number of stores; (2) the number of PBL approvals divided by the number of zoning plans).

Store-level productivity by subsector. Table F.2 the link between heterogeneity in store productivity changes stemming from a more liberal regulation using the alternative measures of regulation. The table presents marginal effects for individual stores when 
one additional PBL application is approved. These marginal effects are computed using the observed number of stores and zoning plans in a local market. For both regulation measures, a more liberal regulation increases store productivity for all subsectors. The average store increases productivity by $0.1-2$ percent for most subsectors. In addition, there is variation in the impact of regulations across stores, as indicated by the standard deviations of the marginal effects. These results are consistent with those reported in Section 5.2 in the paper.

Aggregate local market productivity For each regulation measure, we evaluate the change in aggregate local market productivity in each subsector when increasing the number of approved PBL applications by one. To do so, we sum the marginal effect of all stores in each local market and year, which is based on stores' actual values of previous productivity and regulation, using output market shares as weights. This is interpreted as what would happen to weighted aggregate local market productivity if the regulation become more liberal.

Table F.3 shows the distribution of annual changes in local market productivity with one more PBL approvals (with the number of stores and the number of zoning plans, respectively, held constant) The findings show substantial heterogeneity in the effect of regulation on aggregate productivity across local markets and subsectors. Average local market productivity increases approximately 0.1-3 percent in most subsectors. These results are consistent with the findings in Section 5.3 in the paper. 
Table F.1: Value-added generating function estimates: nonparametric approach

\begin{tabular}{|c|c|c|c|c|c|c|c|c|c|}
\hline & \multicolumn{2}{|c|}{ Labor } & \multicolumn{2}{|c|}{ Capital } & \multicolumn{2}{|c|}{ Demand } & \multicolumn{2}{|c|}{ Markup } & \multirow[t]{2}{*}{ No. of obs. } \\
\hline & $(1)$ & $(2)$ & $(1)$ & (2) & $(1)$ & $(2)$ & $(1)$ & $(2)$ & \\
\hline Textiles & $\begin{array}{c}0.370 \\
(0.011)\end{array}$ & $\begin{array}{c}0.603 \\
(0.002)\end{array}$ & $\begin{array}{c}0.305 \\
(0.015)\end{array}$ & $\begin{array}{c}0.109 \\
(0.007)\end{array}$ & -3.299 & -5.351 & 1.43 & 1.22 & 1,548 \\
\hline Clothing & $\begin{array}{c}0.653 \\
(0.001)\end{array}$ & $\begin{array}{c}0.950 \\
(0.002)\end{array}$ & $\begin{array}{c}0.134 \\
(0.001)\end{array}$ & $\begin{array}{c}0.047 \\
(0.001)\end{array}$ & -6.000 & -10.888 & 1.19 & 1.10 & 13,308 \\
\hline Footwear & $\begin{array}{c}0.406 \\
(0.002)\end{array}$ & $\begin{array}{c}0.640 \\
(0.001)\end{array}$ & $\begin{array}{c}0.388 \\
(0.001)\end{array}$ & $\begin{array}{c}0.131 \\
(0.001)\end{array}$ & -3.131 & -4.981 & 1.46 & 1.25 & 3,207 \\
\hline Furniture & $\begin{array}{c}0.250 \\
(0.020)\end{array}$ & $\begin{array}{c}0.223 \\
(0.028)\end{array}$ & $\begin{array}{c}0.327 \\
(0.003)\end{array}$ & $\begin{array}{c}0.408 \\
(0.019)\end{array}$ & -1.527 & -1.892 & 2.89 & 2.12 & 8,674 \\
\hline Electronics & $\begin{array}{c}0.653 \\
(0.003)\end{array}$ & $\begin{array}{c}0.658 \\
(0.004)\end{array}$ & $\begin{array}{c}0.167 \\
(0.001)\end{array}$ & $\begin{array}{c}0.085 \\
(0.001)\end{array}$ & -4.824 & -6.409 & 1.26 & 1.18 & 7,087 \\
\hline Hardware & $\begin{array}{c}0.685 \\
(0.005)\end{array}$ & $\begin{array}{c}0.595 \\
(0.052)\end{array}$ & $\begin{array}{c}0.165 \\
(0.005)\end{array}$ & $\begin{array}{c}0.388 \\
(0.071)\end{array}$ & -6.469 & -3.939 & 1.18 & 1.34 & 7,474 \\
\hline Books & $\begin{array}{c}0.520 \\
(0.002)\end{array}$ & $\begin{array}{c}0.524 \\
(0.002)\end{array}$ & $\begin{array}{c}0.125 \\
(0.001)\end{array}$ & $\begin{array}{c}0.118 \\
(0.003)\end{array}$ & -2.320 & -1.331 & 1.75 & 4.01 & 3,054 \\
\hline Sports & $\begin{array}{c}0.615 \\
(0.002)\end{array}$ & $\begin{array}{c}0.636 \\
(0.002)\end{array}$ & $\begin{array}{c}0.176 \\
(0.001)\end{array}$ & $\begin{array}{c}0.167 \\
(0.001)\end{array}$ & -6.429 & -6.511 & 1.18 & 1.18 & 6,051 \\
\hline Watches & $\begin{array}{c}0.689 \\
(0.028)\end{array}$ & $\begin{array}{c}0.615 \\
(0.001)\end{array}$ & $\begin{array}{c}0.326 \\
(0.084)\end{array}$ & $\begin{array}{c}0.367 \\
(0.046)\end{array}$ & -2.704 & -1.946 & 1.58 & 2.05 & 3,242 \\
\hline Toys & $\begin{array}{c}0.118 \\
(0.067)\end{array}$ & $\begin{array}{c}0.018 \\
(0.060)\end{array}$ & $\begin{array}{c}0.366 \\
(0.006)\end{array}$ & $\begin{array}{c}0.384 \\
(0.009)\end{array}$ & -1.583 & -1.379 & 2.71 & 3.63 & 1,269 \\
\hline Computers & $\begin{array}{c}0.730 \\
(0.007)\end{array}$ & $\begin{array}{c}0.730 \\
(0.094) \\
\end{array}$ & $\begin{array}{c}0.160 \\
(0.001) \\
\end{array}$ & $\begin{array}{c}0.160 \\
(0.001)\end{array}$ & -3.023 & -3.023 & 1.49 & 1.49 & 6,676 \\
\hline
\end{tabular}

PBL approvals divided by the total number of stores; (2) - number of PBL approvals divided by the number of zoning plans. Standard errors are reported in parentheses. Labor is measured as number of full-time adjusted employees. All regressions include year dummies. $N P_{l m}$ is two-step estimation using a nonparametric labor demand function as proxy for productivity and controlling for imperfect competition. The estimated coefficients include elasticity, i.e., $\left(1+\frac{1}{\eta}\right) \beta_{l}$ for labor and $\left(1+\frac{1}{\eta}\right) \beta_{k}$ for capital. Specification (1) includes previous year's number of PBL approvals divided by the number of stores in the productivity process. Specification (2) includes previous year's number of PBL approvals divided by the number of zoning plans in the productivity process. Market output is measured as the market share weighted output in the municipality. Demand refers to the elasticity of substitution. Markup is defined as price over marginal cost. 
Table F.2: The impact of regulation on store productivity using nonparametric estimation

\begin{tabular}{|c|c|c|c|c|c|c|c|c|c|c|c|}
\hline Subsector & Mean & Std.dev. & Adj. $R^{2}$ & & pport & Mean & Std.dev. & Adj. $R^{2}$ & & Support & \multirow{2}{*}{$\begin{array}{c}\text { No. of obs. } \\
1,079\end{array}$} \\
\hline Textile & 0.0085 & 0.0049 & 0.543 & 0.0052 & $0.0222]$ & 0.0004 & 0.0024 & 0.357 & {$[-0.0066$} & $0.0020]$ & \\
\hline Clothing & 0.0013 & 0.0002 & 0.295 & 0.0005 & $0.0014]$ & 0.0004 & 0.0011 & 0.207 & {$[-0.0009$} & $0.0029]$ & 9,677 \\
\hline Furniture & 0.0012 & 0.0004 & 0.615 & 0.0002 & $0.0019]$ & 0.0059 & 0.0030 & 0.608 & {$[0.0026$} & $0.0132]$ & 6,336 \\
\hline Electronics & 0.0006 & 0.0009 & 0.370 & {$[-0.0019$} & $0.0012]$ & 0.0019 & 0.0032 & 0.388 & {$[-0.0024$} & $0.0088]$ & 5,290 \\
\hline Hardware & 0.0016 & 0.0004 & 0.343 & 0.0013 & $0.0028]$ & 0.0095 & 0.0031 & 0.463 & {$[0.0008$} & $0.0127]$ & 5,597 \\
\hline Books & 0.0068 & 0.0037 & 0.527 & {$[-0.0021$} & $0.0099]$ & 0.0100 & 0.0074 & 0.606 & {$[-0.0002$} & $0.0262]$ & 2,261 \\
\hline Toys & 0.0052 & 0.0077 & 0.603 & {$[-0.0150$} & $0.0122]$ & 0.0005 & 0.0093 & 0.626 & {$[-0.0281$} & $0.0059]$ & 899 \\
\hline Computers & 0.0028 & 0.0040 & 0.370 & {$[-0.0024$} & $0.0111]$ & 0.0002 & 0.0006 & 0.807 & {$[-0.0007$} & $0.0013]$ & 4,804 \\
\hline
\end{tabular}

NOTE: This table shows means and standard deviations, across local markets and years, of the median marginal effect on stores' productivity when an additional PBL application is approved (with number of stores and number of zoning plans held constant, respectively). Marginal effects are computed for individual stores using their observed values of previous productivity and the regulation measure. The OLS estimator is used to estimate the controlled Markov process. The support is computed using 1,000 simulation draws from the estimated distribution of productivity. 
Table F.3: Percentage changes in aggregate local market productivity following a more liberal regulation

\begin{tabular}{|c|c|c|c|c|c|c|c|c|}
\hline \multirow[b]{2}{*}{ Subsector } & \multicolumn{4}{|c|}{$\begin{array}{l}\text { Number of PBL approvals } \\
\text { divided by number of stores }\end{array}$} & \multicolumn{4}{|c|}{$\begin{array}{l}\text { Number of PBL approvals } \\
\text { divided by number of zoning plans }\end{array}$} \\
\hline & $\begin{array}{l}\text { 25th perc. } \\
(\%)\end{array}$ & $\begin{array}{l}\text { Median } \\
(\%)\end{array}$ & $\begin{array}{l}\text { 75th perc. } \\
(\%)\end{array}$ & $\begin{array}{c}\text { Mean } \\
(\%)\end{array}$ & $\begin{array}{l}\text { 25th perc. } \\
(\%)\end{array}$ & $\begin{array}{l}\text { Median } \\
(\%)\end{array}$ & $\begin{array}{l}\text { 75th perc. } \\
(\%)\end{array}$ & $\begin{array}{c}\text { Mean } \\
(\%)\end{array}$ \\
\hline Textile & 0.40 & 0.86 & 1.37 & 1.76 & -0.08 & 0.08 & 0.38 & 0.24 \\
\hline Clothing & 0.15 & 0.31 & 0.49 & 0.62 & -0.02 & 0.02 & 0.07 & 0.10 \\
\hline Footwear & 0.17 & 0.42 & 0.70 & 0.99 & -0.02 & 0.02 & 0.07 & 0.10 \\
\hline Furniture & -0.21 & 0.61 & 0.80 & 1.40 & 0.30 & 0.82 & 1.23 & 1.65 \\
\hline Electronics & -0.14 & 0.01 & 0.17 & 0.31 & 0.30 & 0.82 & 1.23 & 1.65 \\
\hline Hardware & 0.06 & 0.20 & 0.21 & 0.46 & 0.57 & 1.33 & 1.99 & 2.63 \\
\hline Books & 0.32 & 0.87 & 1.39 & 1.89 & -0.05 & 0.73 & 2.75 & 3.11 \\
\hline Sports & 0.04 & 0.13 & 0.20 & 0.32 & -0.08 & 0.30 & 1.90 & 1.50 \\
\hline Watches & 0.08 & 0.27 & 0.34 & 0.57 & 0.25 & 0.64 & 1.05 & 1.33 \\
\hline Toys & 0.18 & 0.95 & 1.56 & 2.21 & -0.75 & 0.22 & 0.80 & 1.25 \\
\hline Computers & -0.00 & 0.16 & 0.38 & 0.56 & -0.75 & 0.22 & 0.80 & 1.25 \\
\hline
\end{tabular}

NOTE: This table shows summary statistics of the percentage changes in aggregate local market productivity when an additional PBL application is approved (with number of stores and number of zoning plans held constant, respectively). Marginal effects are computed for individual stores using their observed values of previous productivity and the regulation measure. Municipalities (290 in total) are used as local markets. Marginal effects for individual stores are used (Table F.2) with output market shares as weights. 


\section{Appendix F.2 Regulation index}

This subsection presents estimation results using the regulation index presented in Section 2 in the paper. To construct an index variable, we combine the share of non-socialist seats in the local government, the the number of PBL approvals divided by the number of zoning plans, and the number of PBL approvals divded by the number of stores. In the main index variable specification, we apply half of the weight to the share of non-socialist seats and one-quarter each to the two measures of PBL approvals. To simplify the evaluation of the marginal effects of how a more liberal regulation changes store's productivity, we standardize the regulation index to a mean of zero and a standard deviation of one.

Service production function estimates. The NP estimators use an endogenous Markov process for productivity, i.e., future productivity is a nonparametric function of current productivity and a regulation index that measures the degree of regulation. The results rely on the standardized version of the regulation index constructed as a weighted sum of three variables that are independent of market size, i.e., share of non-socialist seats, share of PBL approvals (PBL approvals divided by number of zoning plans) and number of PBL approvals per number of stores for each municipality and year (Section 2 in the paper). ${ }^{7}$

The OLS and NP results suggest the importance of controlling for simultaneity, selection, and price biases when estimating the service production function. First, the coefficient of labor decreases when using NP estimators (simultaneity bias). Books, computers and electronics are the subsectors with the highest labor elasticity, and books and furniture have the highest capital elasticity. Second, the coefficient of capital increases in most subsectors when controlling for local market characteristics ( $\mathrm{NP}_{l m}$ estimator). This has the same effect as controlling for the selection bias, i.e., adding the estimated survival

\footnotetext{
${ }^{7}$ Our study shares the common obstacle of not observing one ideal measure of regulation with previous work on land use and entry regulations. A valid alternative to the index variable is to use only the share (and number) of approved applications and/or political preferences (Bertrand and Kramarz, 2002; Schivardi and Viviano, 2011; Sadun, 2014). One could argue that the number of applications (and rejections) is not completely exogenous if the number of applications is easily influenced by current local government policies.
} 
probability as a control in the productivity process (Olley and Pakes, 1996). Third, not controlling for unobserved prices creates a downward bias in the scale estimator (Klette and Griliches, 1996). The returns to scale is higher after controlling for prices in $\mathrm{NP}_{l m}$ than in OLS and $\mathrm{NP}_{l}$. For several subsectors, at least one of the coefficients of labor and capital are larger after controlling for prices (column (2) in Table F.4).

A key feature of the $\mathrm{NP}_{l m}$ estimator is that we obtain an estimate of the demand elasticity for each subsector. The average estimated demand elasticity across subsectors is -4.30 , varying between -8.43 (clothing) and -1.31 (books). There is an inverse relationship between estimated demand elasticity and the implied markup, i.e., the subsectors with large demand elasticity have low markups. The average markup (price over marginal cost) across subsectors is 1.76, and it ranges from 1.13 (clothing) to 3.12 (furniture). A high degree of product differentiation might explain the observed large values for the markups in some subsectors. Clothing, electronics and sports have relatively low markups and high exit rates (Table 2 in the paper). In subsectors with high demand elasticity, there are small differences between the labor and capital coefficients from the quantity and value-added service production functions, e.g., electronics and sports. For subsectors with low demand elasticity, we have high estimates of the returns to scale.

Store-level productivity by subsector. Table F.6 documents the link between heterogeneity in store productivity changes stemming from a more liberal regulation. We present marginal effects for individual stores when the regulation index increases by one standard deviation. To keep the presentation tractable, we focus on the median marginal effect in each local market and present the mean and standard deviation across local markets and years. A more liberal regulation increases store productivity for virtually all subsectors. The median store increases productivity by $2-4$ percent on average for most subsectors. The marginal effects remain similar if we use equal weights for each of the three measures in the regulation index, i.e., $(0.33,0.33,033)$ weights instead of $(0.5,0.25,0.25)$ weights. In addition, there is variation in the impact of regulations across local markets, as indicated by the standard deviations of the marginal effects. 
Clothing, footwear and books have the largest marginal effects. This result may be associated with the fact that these subsectors have relatively high rates of net exit, forcing incumbents to increase their productivity, and that footwear and books are subsectors with relatively low mean value-added growth (Tables B.1-2).

We also present the support of the impact of a more liberal regulation on productivity. For each subsector, the support is determined based on 1,000 simulated values from all parts of the productivity distribution. The support provides additional information on the heterogeneity of how productivity changes with a more liberal regulation and complements the mean marginal effects. Large and positive upper bounds in clothing, footwear and books indicate that some stores obtain substantial productivity gains from a more liberal regulation in these subsectors. These bounds also confirm the relatively large mean marginal effects in these subsectors. The negative lower bounds in toys and computers are in line with the fact that these subsectors also have relatively small mean marginal effects.

An advantage of our two-step modeling framework is the identification strategy of the effect of regulation on productivity. We control for demand, remove the demand shocks in the first-stage of estimation, and allow productivity to be correlated over time and regulation to have a feedback on productivity. These actions also allow for a nonlinear productivity process, which is important when there is heterogeneity in stores' responses to changes in the regulation.

In comparing the average marginal effect of regulation on productivity in Table F.6 with the results from the descriptive analysis of multi-factor productivity in Table F.5, we find larger marginal effects in seven out of eleven retail subsectors using the structural approach. These findings are in line with the theory predictions because the effect from a simple parametric regression measures the impact on both productivity and prices. A more liberal regulation may induce an increase in competition and then a decrease in prices, which gives a net effect smaller when using a simple parametric approach. The structural approach implicitly controls for simultaneity and selection biases, which 
affect the productivity measure and the marginal effects owing to the nonlinearity of the productivity process.

To investigate the sensitivity of the marginal effects of regulation on productivity in the structural approach, we use simulation methods. Estimation results of the endogenous productivity process based on productivity recovered from a service production function with different coefficients on labor and capital than those in our main specification $\left(\mathrm{NP}_{l m}\right.$ in Table 6) show changes in the marginal effects of regulation on productivity. ${ }^{8}$ In sum, the results from the simulations and the comparison between the nonparametric twostep approach with a nonlinear and endogenous productivity process and the simple parametric specification emphasize the importance of using sophisticated methods to accurately estimate productivity and evaluate how it changes with the regulation.

Aggregate local market productivity. A key issue for policymakers is to assess the change in aggregated local market productivity when the regulation becomes more liberal. To quantify the cost of regulations in terms of changes in local market productivity is a first step toward a more complete welfare analysis of entry regulations. The magnitude of these effects can thus be put in contrast to other demand and supply side aspects that local authorities should evaluate when evaluating the consequences of a new entrant. In Sweden, municipalities have to consider the availability of stores and store product assortment, prices, market shares and traffic, for example.

We evaluate the change in aggregated local market productivity when increasing the regulation index by one standard deviation. To do so, we sum over the marginal effect of all stores in each local market and year, which is based on stores' actual values of previous productivity and regulation, using output market shares as weights. This is interpreted as what would happen to weighted aggregated local market productivity if the regulation become more liberal. Table F.7 shows the distribution of annual changes in local market productivity with a more liberal regulation. There are substantial differences between subsectors. Median local market productivity increases approximately $2-5$ percent in most

\footnotetext{
${ }^{8}$ The simulations are available from the authors upon request.
} 
subsectors, but it increases to at most 13 percent (clothing). Across all subsectors, the corresponding increase in aggregated median local market productivity is on average 3.5 percent. A majority of subsectors have a small difference between the mean and median, with a 75th percentile increase in local market productivity that is roughly double that of the 25th percentile. Toys, computers, hardware and electronics are examples of subsectors with relatively high dispersion of changes in local market productivity owing to a more liberal regulation. For toys and computers, this may relate to the high share of large entrants (Table 2) and the relatively high mean growth in value-added and number of employees (Table B.2). In addition, it ties back to the negative support of the store-level marginal effects for these subsectors.

\section{Decomposition of changes in local market productivity from a more liberal}

regulation. The next step is to understand the contribution of observed changes in the local market regulation to the weighted aggregated productivity growth in market $m$ in period $t$. To do this, we construct a productivity decomposition based on total differentiation of the productivity process, i.e.,

$$
d \omega_{j t}=\frac{\partial g(\cdot)}{\partial \omega_{j t-1}} d \omega_{j t-1}+\frac{\partial g(\cdot)}{\partial r_{m t-1}} d r_{m t-1}
$$

Using the discrete version of (F-9), we can write the weighted productivity growth in local market $m$ as

$$
\begin{aligned}
\Delta \omega_{m t} & \equiv \sum_{j \in m} s_{j t} \omega_{j t}-\sum_{j \in m} s_{j t-1} \omega_{j t-1} \\
& \simeq \sum_{j \in m} s_{j t} \frac{\partial g(\cdot)}{\partial \omega_{j t-1}} \Delta \omega_{j t-1}+\sum_{j \in m} s_{j t} \frac{\partial g(\cdot)}{\partial r_{m t-1}} \Delta r_{m t-1} \\
& +\sum_{j \in m} \Delta s_{j t} \omega_{j t-1}
\end{aligned}
$$

where $s_{j t}$ is the market share of store $j$ that operates in local market $m$ in period $t$. The first term of the decomposition shows the contribution to the local productivity growth attributable to factors other than regulation. The second term shows the contribution to local productivity growth attributable to changes in the local regulation. The third term 
is the contribution to productivity growth of stores that increased their market shares at the initial productivity level. The change $\Delta r_{m t-1}$ includes the actual changes in the regulation that we observe directly in the data.

Table F.8 presents the median of each term in the decomposition based on the observed market-year values. This simplifies the exposition and implies that the sum of the computed medians of the three terms in the decompositions is not equal to the weighted aggregated productivity growth in local markets. The results show substantial heterogeneity in yearly productivity growth across local markets. The median aggregated productivity growth increases on average by 3.3 percentage points across all subsectors. The contribution from observed changes in the regulation is on average 0.12 percentage points across all subsectors (second term). This relies on all actual changes in the regulation in our data. Hence, there is a net positive contribution from the de facto observed changes in the regulation. The largest contribution comes, as expected, from productivity growth within firms independent of current changes in the regulation (first term). This confirms previous findings of persistent productivity differences across firms. There is a positive, though relatively small, contribution from stores that increase their market shares for a given productivity (third term). These findings suggest that a more liberal regulation can make a non-trivial contribution to aggregated productivity growth, especially in subsectors where the within productivity is small.

The main focus is on the second term in this decomposition (explained in detail below). It is important to note that by discritizing the equation (F-9) we introduce small numerical errors (i.e., replace $d r_{m t-1}$ by $\Delta r_{m t-1}$ ). Second, by standardizing the regulation measure, the term $\Delta r_{m t-1}$ becomes small. Because of the standardization, we also expect that the marginal effect of regulation to be small. Therefore by multiplying two small numbers, we get a smaller number. The standardization helps in interpreting the marginal effect of a complex regulation measure, but also introduces difficulties in understanding from where it comes the 1 percent increase in the regulation index constructed as a weighted sum of three variables. In the paper, the interpretation of the marginal 
effect of regulation is straightforward since it can be related to the change in productivity due to one additional approval. Even if the marginal effects of one additional approval is small, a median market has about 10 approvals per year, which might imply a substantial effect of regulation. 
Table F.4: Value-added generating function estimates: nonparametric approach

\begin{tabular}{|c|c|c|c|c|c|c|c|c|c|c|c|}
\hline & \multicolumn{2}{|c|}{$O L S$} & \multicolumn{2}{|c|}{$N P_{l}$} & \multicolumn{6}{|c|}{$N P_{l m}$} & \multirow[b]{3}{*}{ No. of obs. } \\
\hline & \multirow[t]{2}{*}{ Labor } & \multirow[t]{2}{*}{ Capital } & \multirow[t]{2}{*}{ Labor } & \multirow[t]{2}{*}{ Capital } & \multicolumn{2}{|c|}{ Labor } & \multicolumn{2}{|c|}{ Capital } & \multirow[t]{2}{*}{ Demand } & \multirow[t]{2}{*}{ Markup } & \\
\hline & & & & & (1) & (2) & (1) & $(2)$ & & & \\
\hline Textiles & $\begin{array}{c}0.821 \\
(0.020)\end{array}$ & $\begin{array}{c}0.123 \\
(0.010)\end{array}$ & $\begin{array}{c}0.856 \\
(0.025)\end{array}$ & $\begin{array}{c}0.321 \\
(0.013)\end{array}$ & $\begin{array}{c}0.640 \\
(0.002)\end{array}$ & 0.785 & $\begin{array}{c}0.101 \\
(0.001)\end{array}$ & 0.124 & -5.39 & 1.23 & 1,623 \\
\hline Clothing & $\begin{array}{c}0.757 \\
(0.007)\end{array}$ & $\begin{array}{c}0.120 \\
(0.004)\end{array}$ & $\begin{array}{c}0.417 \\
(0.015)\end{array}$ & $\begin{array}{c}0.311 \\
(0.008)\end{array}$ & $\begin{array}{c}0.752 \\
(0.001)\end{array}$ & 0.853 & $\begin{array}{c}0.073 \\
(0.001)\end{array}$ & 0.083 & -8.43 & 1.13 & 12,625 \\
\hline Footwear & $\begin{array}{c}0.735 \\
(0.011)\end{array}$ & $\begin{array}{c}0.121 \\
(0.006)\end{array}$ & $\begin{array}{c}0.802 \\
(0.002)\end{array}$ & $\begin{array}{c}0.112 \\
(0.001)\end{array}$ & $\begin{array}{c}0.433 \\
(0.002)\end{array}$ & 0.730 & $\begin{array}{c}0.329 \\
(0.001)\end{array}$ & 0.555 & -2.45 & 1.68 & 3,188 \\
\hline Furniture & $\begin{array}{c}0.814 \\
(0.008)\end{array}$ & $\begin{array}{c}0.135 \\
(0.005)\end{array}$ & $\begin{array}{c}0.332 \\
(0.011)\end{array}$ & $\begin{array}{c}0.029 \\
(0.005)\end{array}$ & $\begin{array}{c}0.265 \\
(0.082)\end{array}$ & 0.830 & $\begin{array}{c}0.327 \\
(0.010)\end{array}$ & 1.023 & -1.47 & 3.12 & 8,203 \\
\hline Electronics & $\begin{array}{c}0.821 \\
(0.008)\end{array}$ & $\begin{array}{c}0.144 \\
(0.004)\end{array}$ & $\begin{array}{c}0.739 \\
(0.011)\end{array}$ & $\begin{array}{c}0.391 \\
(0.005)\end{array}$ & $\begin{array}{l}0.916 \\
(0.485)\end{array}$ & 1.078 & $\begin{array}{c}0.381 \\
(0.131)\end{array}$ & 0.448 & -6.65 & 1.17 & 6,897 \\
\hline Hardware & $\begin{array}{c}0.782 \\
(0.007)\end{array}$ & $\begin{array}{c}0.189 \\
(0.004)\end{array}$ & $\begin{array}{c}0.551 \\
(0.014)\end{array}$ & $\begin{array}{c}0.196 \\
(0.008)\end{array}$ & $\begin{array}{c}0.684 \\
(0.005)\end{array}$ & 0.829 & $\begin{array}{c}0.171 \\
(0.004)\end{array}$ & 0.207 & -5.73 & 1.21 & 7,067 \\
\hline Books & $\begin{array}{c}0.737 \\
(0.012)\end{array}$ & $\begin{array}{c}0.149 \\
(0.007)\end{array}$ & $\begin{array}{c}0.824 \\
(0.005)\end{array}$ & $\begin{array}{c}0.143 \\
(0.002)\end{array}$ & $\begin{array}{c}0.474 \\
(0.015)\end{array}$ & 1.973 & $\begin{array}{c}0.180 \\
(0.006)\end{array}$ & 0.751 & -1.31 & 4.16 & 2,922 \\
\hline Sports & $\begin{array}{c}0.744 \\
(0.009)\end{array}$ & $\begin{array}{c}0.141 \\
(0.005)\end{array}$ & $\begin{array}{c}0.431 \\
(0.023)\end{array}$ & $\begin{array}{c}0.485 \\
(0.013)\end{array}$ & $\begin{array}{c}0.645 \\
(0.002)\end{array}$ & 0.753 & $\begin{array}{c}0.162 \\
(0.001)\end{array}$ & 0.189 & -6.96 & 1.17 & 5,796 \\
\hline Watches & $\begin{array}{c}0.804 \\
(0.012)\end{array}$ & $\begin{array}{c}0.101 \\
(0.006)\end{array}$ & $\begin{array}{c}0.679 \\
(0.012)\end{array}$ & $\begin{array}{c}0.367 \\
(0.006)\end{array}$ & $\begin{array}{c}0.254 \\
(0.019)\end{array}$ & 0.378 & $\begin{array}{c}0.354 \\
(0.008)\end{array}$ & 0.527 & -3.04 & 1.48 & 3,156 \\
\hline Toys & $\begin{array}{c}0.682 \\
(0.021)\end{array}$ & $\begin{array}{l}0.216 \\
(0.013)\end{array}$ & $\begin{array}{c}0.662 \\
(0.012)\end{array}$ & $\begin{array}{c}0.476 \\
(0.006)\end{array}$ & $\begin{array}{c}0.461 \\
(0.003)\end{array}$ & 0.699 & $\begin{array}{c}0.188 \\
(0.004)\end{array}$ & 0.285 & -2.93 & 1.51 & 1,208 \\
\hline Computers & $\begin{array}{c}0.795 \\
(0.009)\end{array}$ & $\begin{array}{c}0.212 \\
(0.006)\end{array}$ & $\begin{array}{c}0.108 \\
(0.026)\end{array}$ & $\begin{array}{c}0.317 \\
(0.007)\end{array}$ & $\begin{array}{c}0.728 \\
(0.007)\end{array}$ & 1.095 & $\begin{array}{c}0.160 \\
(0.001)\end{array}$ & 0.240 & -2.98 & 1.50 & 6,350 \\
\hline
\end{tabular}

NOTE: The dependent variable is log of deflated value-added. Standard errors are reported in parentheses. Labor is measured as number of Fraser's (2006) two-step estimation method using labor as proxy for productivity; $N P_{l m}$ is two-step estimation using a nonparametric labor demand function as proxy for productivity and controlling for imperfect competition. Columns (1) shows estimated coefficients including elasticity, i.e., $\left(1+\frac{1}{n}\right) \beta_{l}$ for labor and $\left(1+\frac{1}{n}\right) \beta_{k}$ for capital; columns (2) show the estimated coefficients without elasticity. All $N P$ specifications include previous year's regulation index in the productivity process (Section 2), current capital stock and previous labor are used as instruments and standard errors are computed using Ackerberg, Chen, and Hahn (2011). Market output is measured as the market share weighted output in the municipality. Demand refers to the elasticity of substitution. Markup is defined as price over marginal cost. 
Table F.5: The impact of regulation on productivity without local market and price controls

\begin{tabular}{|c|c|c|c|}
\hline & $\begin{array}{r}\text { Regulation } \\
(1)\end{array}$ & $\begin{array}{r}\text { Adjusted } \mathrm{R}^{2} \\
(2)\end{array}$ & $\begin{array}{r}\text { No. Obs. } \\
(3)\end{array}$ \\
\hline Textile & $\begin{array}{l}0.0207 \\
(0.012)\end{array}$ & 0.63 & 1,079 \\
\hline Clothing & $\begin{array}{r}0.0171 \\
(0.004)\end{array}$ & 0.65 & 9,677 \\
\hline Footwear & $\begin{array}{r}0.0455 \\
(0.008)\end{array}$ & 0.73 & 2,386 \\
\hline Furniture & $\begin{array}{r}0.0201 \\
(0.005)\end{array}$ & 0.69 & 6,336 \\
\hline Electronics & $\begin{array}{r}0.0191 \\
(0.006)\end{array}$ & 0.68 & 5,290 \\
\hline Hardware & $\begin{array}{r}0.0166 \\
(0.004)\end{array}$ & 0.77 & 5,597 \\
\hline Books & $\begin{array}{r}0.0296 \\
(0.007)\end{array}$ & 0.72 & 2,261 \\
\hline Sports & $\begin{array}{r}0.0053 \\
(0.005)\end{array}$ & 0.69 & 2,261 \\
\hline Watches & $\begin{array}{r}0.0369 \\
(0.008)\end{array}$ & 0.63 & 2,468 \\
\hline Toys & $\begin{array}{r}0.0143 \\
(0.013)\end{array}$ & 0.71 & 899 \\
\hline Computers & $\begin{array}{r}0.0675 \\
(0.006) \\
\end{array}$ & 0.80 & 4,804 \\
\hline
\end{tabular}

NOTE: Column (1) shows the estimated coefficient of regulation $\left(\beta_{r}\right)$ from the following regression equation: $y_{j t}=$ $\beta_{0}+\beta_{l} l_{j t}+\beta_{k} k_{j t}+\beta_{r} r_{m t}+u_{j t}$, where $u_{j t}$ are i.i.d. The regulation index is used as regulation measure (Section 2). The OLS estimator is used.

Table F.6: The impact of regulation on store productivity using nonparametric estimation

\begin{tabular}{lrllrlr}
\hline \hline & & & & & & \\
Subsector & Mean & Std.dev. & Adj. $R^{2}$ & No. of obs. & \multicolumn{2}{c}{ Support } \\
\hline Textile & 0.031 & 0.015 & 0.376 & 1,079 & {$[0.027$,} & $0.073]$ \\
Clothing & 0.142 & 0.061 & 0.635 & 9,677 & {$[0.155$,} & $0.484]$ \\
Footwear & 0.133 & 0.068 & 0.796 & 2,386 & {$[0.099$,} & $0.640]$ \\
Furniture & -0.111 & 0.032 & 0.645 & 6,336 & {$[-0.147$,} & $-0.066]$ \\
Electronics & 0.018 & 0.019 & 0.440 & 5,290 & {$[0.016$,} & $0.062]$ \\
Hardware & 0.021 & 0.019 & 0.378 & 5,597 & {$[0.025$,} & $0.048]$ \\
Books & 0.094 & 0.061 & 0.628 & 2,261 & {$[0.054$,} & $0.279]$ \\
Sports & 0.043 & 0.008 & 0.305 & 4,358 & {$[0.045$,} & $0.074]$ \\
Watches & 0.035 & 0.027 & 0.656 & 2,468 & {$[0.016$,} & $0.135]$ \\
Toys & 0.020 & 0.038 & 0.404 & 899 & {$[-0.059$,} & $0.072]$ \\
Computers & -0.002 & 0.034 & 0.371 & 4,804 & {$[-0.010$,} & $0.052]$ \\
\hline \hline
\end{tabular}

NOTE: This table shows means and standard deviations, across local markets and years, of the median marginal effect on stores' productivity when the regulation index changes by one standard deviation. Marginal effects are computed for individual stores using their observed values of previous productivity and the regulation index. The regulation index is defined in Section 2. The OLS estimator is used. The support is computed using 1,000 simulation draws from the estimated distribution of productivity. 
Table F.7: Change in aggregate local market productivity following more liberal regulation

\begin{tabular}{lccccc}
\hline \hline & & & & & \\
Subsector & 25th perc. & Median & 75 th perc. & Mean & Std. dev. \\
\hline Textile & 0.019 & 0.029 & 0.037 & 0.029 & 0.015 \\
Clothing & 0.089 & 0.134 & 0.173 & 0.130 & 0.057 \\
Footwear & 0.088 & 0.117 & 0.166 & 0.129 & 0.066 \\
Furniture & -0.126 & -0.108 & -0.080 & -0.098 & 0.036 \\
Electronics & 0.006 & 0.020 & 0.031 & 0.017 & 0.017 \\
Hardware & 0.012 & 0.026 & 0.035 & 0.021 & 0.018 \\
Books & 0.053 & 0.071 & 0.107 & 0.087 & 0.056 \\
Sports & 0.035 & 0.043 & 0.047 & 0.041 & 0.010 \\
Watches & 0.019 & 0.033 & 0.055 & 0.038 & 0.029 \\
Toys & -0.008 & 0.015 & 0.046 & 0.021 & 0.038 \\
Computers & -0.016 & 0.006 & 0.024 & 0.002 & 0.031 \\
\hline \hline
\end{tabular}

NOTE: This table shows summary statistics of the changes in aggregate local market productivity when the regulation index increases by one standard deviation. Municipalities (290 in total) are used as local markets. Marginal effects for individual stores are used (Table F.6) with output market shares as weights.

Table F.8: Decomposition: The impact of regulation on weighed aggregate productivity growth in local markets

\begin{tabular}{|c|c|c|c|c|}
\hline & \multicolumn{4}{|c|}{ Median } \\
\hline & $\begin{array}{r}\text { Productivity } \\
\text { growth } \\
(1)\end{array}$ & $\begin{array}{r}\text { Change due to } \\
\text { regulation } \\
(2)\end{array}$ & $\begin{array}{l}\text { Change due to } \\
\text { internal factors }\end{array}$ & $\begin{array}{r}\text { Change in } \\
\text { market share } \\
(4)\end{array}$ \\
\hline Textile & 0.0737 & 0.0011 & 0.0360 & 0.0002 \\
\hline Clothing & 0.1559 & 0.0051 & 0.0553 & 0.0001 \\
\hline Footwear & 0.0984 & 0.0035 & 0.0326 & 0.0004 \\
\hline Furniture & 0.0306 & -0.0001 & -0.0242 & 0.0005 \\
\hline Electronics & 0.0106 & 0.0009 & -0.0194 & 0.0001 \\
\hline Hardware & 0.0112 & 0.0006 & 0.0048 & -0.0001 \\
\hline Books & 0.0668 & 0.0008 & 0.0691 & 0.0001 \\
\hline Sports & 0.0399 & 0.0003 & 0.0067 & 0.0001 \\
\hline Watches & 0.0112 & 0.0012 & -0.0160 & -0.0000 \\
\hline Toys & 0.0521 & -0.0001 & 0.0123 & 0.0003 \\
\hline Computers & 0.0708 & 0.0005 & 0.0298 & 0.0003 \\
\hline
\end{tabular}

NOTE: Figures represent median values across markets and years. Column (1) shows the median change in weighted productivity growth across markets between year $t-1$ and $t$. Column (2) shows median contribution to local market productivity growth of stores associated with a one standard deviation increase in the regulation index. Column (3) shows median contribution to local market productivity growth that is not associated with regulation. Column (4) shows median contribution to local market productivity growth from stores that increased their market share without changing their productivity. Because we show the median of each decomposition term, the sum $(2)+(3)+(4)$ is different from (1). 


\section{Appendix F.3 Number of PBL approvals}

This appendix discusses the findings using the number of approved PBL applications as proxy for regulation measure. Figure 1 (3D-plot) shows the aggregate relationship across local markets and time between current productivity, previous productivity, and previous number of approved PBL applications in the municipality. The figure aims to provide preliminary information about the productivity process. ${ }^{9}$ Current productivity increases under a more liberal regulatory environment for clothing, footwear, electronics, books, and sports. The corresponding relationship tends to be an inverted-U shaped one for hardware, watches, and computers. There are small differences in current productivity depending on the degree of regulation for furniture and toys, given previous productivity. These subsectors exhibit a strong positive relationship between current and previous productivity. This high persistency in productivity over time also holds for electronics and watches.

Marginal effects for percentiles of local market productivity distributions. Table F.9 presents the marginal effects of the impact of a more liberal entry regulation (one additional PBL approval) on stores' future productivity. The empirical results highlight the heterogeneity in the (net) marginal effect of the regulation on productivity. The table shows averages and standard deviations for different distribution measures across local markets. For each subsector, the impact of the approval of one additional PBL application on productivity is computed for different parts of the productivity distribution in local markets. This result is due to productivity differences across local markets, and the impact of a more liberal regulatory environment might differ for stores with high and low productivity. The marginal effects are computed as follows for the median, for example. First, we compute median productivity in each local market. Second, we use the estimated productivity process to compute the impact of an additional PBL approval on the median store in each local market. Finally, we compute averages and standard

\footnotetext{
${ }^{9}$ The surface is obtained using polynomial approximations of order two on different intervals. In the regression analysis, we approximate the productivity process using a polynomial expansion of order three.
} 
deviations for the marginal effects across local markets. Thus, the mean value for the $x$ th percentile, reported in Table F.9, is the average impact across local markets of a more liberal regulatory environment on the future productivity of a store with current productivity equal to the $x$-th percentile value in its local market.

The results from our full model reveal the following patterns. First, the impact of an additional PBL approval is now positive. Productivity increases by 1.5-2.6 percent in footwear, hardware, clothing, and sports for stores with productivity values between 10th and 90th percentiles. For the median stores, an additional PBL approval increases productivity by approximately 2 percent in most subsectors. Second, the impact of regulation on productivity is larger among low productivity stores (10th percentile) than high productivity stores (90th percentile), e.g., clothing (2.5 and 2.0 percent), footwear (2.6 and 1.7 percent), hardware (2.2 and 1.5 percent), and sports ( 2 and 1.8 percent). Third, the marginal effects are close to zero for watches and negative for books (approximately -2 percent). The books subsector was affected by the increasing competition from on-line stores, e.g., Amazon, Adlibris and Bokus, and had a net exit rate of 4 percent during the study period. Fourth, the highest impact of a more liberal regulatory environment is in computers and furniture (8.2 and 13.1 percent for the 10th percentile, 8.6 and 13.5 percent for the 90th percentile).

Counterfactual exercise. We also calculate the economic cost of the regulation faced by stores. The impact of regulation on productivity is directly linked to the efficiency of the retail sector. Given the use of inputs (labor and capital), we quantify how the degree of regulation affects the effectiveness with which stores use their inputs to generate sales (or value-added). Using information about the marginal effects (Table F.9), our goal is now to calculate the economic cost of a less liberal entry regulation for each subsector and the whole retail sector. ${ }^{10}$ The counterfactuals are not reported in a table but discussed in the text.

\footnotetext{
${ }^{10}$ Greenstone, List, and Syverson (2012) adopt a similar approach when evaluating the economic cost of environmental regulation in the U.S. manufacturing industry. Note that the marginal effects in Table F.9 are at the local market level whereas the counterfactuals are at the aggregate level (sum across all local markets).
} 
An alternative interpretation of the marginal effects is that one fewer approved PBL application decreases median store productivity by between 1 (electronics) and 13 percent (furniture). ${ }^{11}$ Holding labor and capital constant, this is equivalent to a decline in output of 1-13 percent. Store sales for the period 1996-2002 are on average 0.576 million euros (footwear) - 2.887 million euros (clothing). ${ }^{12}$ For a store, this implies that the annual economic cost of one fewer approved PBL application is 0.004 million euros (electronics) 0.143 million euros (computers) on average. ${ }^{13}$ At the subsector level, the annual economic cost of a less liberal regulatory environment ranges from 2.8 million euros (toys) to 194 million euros (furniture). This corresponds to a total subsector cost as high as 20 million euros (toys) - 1,361 million euros (furniture) for the complete time period 1996-2002. ${ }^{14}$

Our estimated economic cost of less liberal entry regulation is intended to be interpreted as a lower bound. The reason is that we compute the values conditional on survival, which implies that the true effect may be larger. ${ }^{15}$ While we control for the effect of regulation on demand, there might still be persistent demand shocks to productivity that are affected by the regulation. Note that we evaluate the cost of one fewer approved PBL application per local market and year in each subsector. Overall, the counterfactual calculations suggest that less liberal entry regulation induces non-trivial economic costs for stores in Swedish retail trade.

\footnotetext{
${ }^{11}$ We exclude three subsectors where the marginal effects of the regulation are close to zero (textiles, books, and hardware).

${ }^{12}$ Numbers are in 2012 values, where $1 \mathrm{EUR}=9.01 \mathrm{SEK}$ and $1 \mathrm{EUR}=1.30 \mathrm{USD}$.

${ }^{13}$ The counterfactual output for store $j$, if the regulation allows for one fewer PBL approval, is calculated as follows: $y_{j}^{C F}=\frac{1}{(1-x)} y_{j}$, where $x$ is the estimated marginal effect of the impact of regulation on productivity and $y_{j}$ is the observed output of store $j$. For simplicity, we consider average output and use values in 2012 euros. For clothing, for example, average store level sales equal 0.605 million euros (1996-2002) and the median marginal effect is 2.2 percent (Table F.9). The annual cost of the regulation is calculated as the difference from the counterfactual level of output, i.e., $\left(\frac{1}{1-0.022}\right) 0.605-0.605$. Under the assumption that firms are price takers, Greenstone, List, and Syverson (2012) also interpret their findings in terms of profits.

${ }^{14}$ The annual subsector cost is computed as the average economic cost per store times the average number of stores in each subsector during the period 1996-2002. The subsector cost for the full period is calculated as the average economic cost per store times the number of stores in the subsector in each of the years from 1996 to 2002.

${ }^{15}$ By controlling for local market characteristics when estimating productivity, we reduce the impact of selection on our productivity estimates. We empirically confirm this in our data, i.e., we find no major changes in the value-added generating function estimates when controlling for selection (results are not reported but are available from the authors on request).
} 
Table F.9: Productivity and entry regulations in local markets: nonparametric approach

\begin{tabular}{|c|c|c|c|c|c|c|c|c|c|}
\hline \multirow[b]{3}{*}{ Textiles } & \multicolumn{5}{|c|}{ Percentile of Productivity ${ }_{t-1}$} & & & \multirow{3}{*}{$\frac{\text { Adj. } R^{2}}{0.397}$} & \multirow{3}{*}{$\frac{\text { No. of obs. }}{1,623}$} \\
\hline & 10th & 25 th & 50 th & 75th & 90th & \multicolumn{2}{|c|}{ Support } & & \\
\hline & $\begin{array}{r}0.0007 \\
(0.003)\end{array}$ & $\begin{array}{c}0.0008 \\
(0.002)\end{array}$ & $\begin{array}{c}0.0009 \\
(0.002)\end{array}$ & $\begin{array}{c}0.0012 \\
(0.002)\end{array}$ & $\begin{array}{c}0.0014 \\
(0.001)\end{array}$ & {$[-0.009$} & $0.002]$ & & \\
\hline Clothing & $\begin{array}{c}0.025 \\
(0.004)\end{array}$ & $\begin{array}{c}0.024 \\
(0.003)\end{array}$ & $\begin{array}{c}0.022 \\
(0.003)\end{array}$ & $\begin{array}{c}0.021 \\
(0.002)\end{array}$ & $\begin{array}{c}0.020 \\
(0.002)\end{array}$ & {$[0.015$, } & $0.032]$ & 0.597 & 12,625 \\
\hline Footwear & $\begin{array}{c}0.026 \\
(0.026)\end{array}$ & $\begin{array}{c}0.024 \\
(0.025)\end{array}$ & $\begin{array}{c}0.021 \\
(0.025)\end{array}$ & $\begin{array}{c}0.018 \\
(0.026)\end{array}$ & $\begin{array}{c}0.017 \\
(0.028)\end{array}$ & {$[0.001$,} & $0.128]$ & 0.848 & 3,188 \\
\hline Furniture & $\begin{array}{c}0.131 \\
(0.004)\end{array}$ & $\begin{array}{c}0.132 \\
(0.003)\end{array}$ & $\begin{array}{c}0.133 \\
(0.003)\end{array}$ & $\begin{array}{c}0.134 \\
(0.002)\end{array}$ & $\begin{array}{c}0.135 \\
(0.002)\end{array}$ & {$[0.123$} & $0.138]$ & 0.579 & 8,203 \\
\hline Electronics & $\begin{array}{c}0.006 \\
(0.001)\end{array}$ & $\begin{array}{c}0.006 \\
(0.001)\end{array}$ & $\begin{array}{c}0.005 \\
(0.001)\end{array}$ & $\begin{array}{c}0.004 \\
(0.001)\end{array}$ & $\begin{array}{c}0.004 \\
(0.001)\end{array}$ & [ 0.004 & $0.008]$ & 0.422 & 6,897 \\
\hline Hardware & $\begin{array}{c}0.022 \\
(0.009)\end{array}$ & $\begin{array}{c}0.021 \\
(0.008)\end{array}$ & $\begin{array}{c}0.018 \\
(0.008)\end{array}$ & $\begin{array}{c}0.016 \\
(0.007)\end{array}$ & $\begin{array}{c}0.015 \\
(0.007)\end{array}$ & {$[0.005$} & $0.038]$ & 0.738 & 7,067 \\
\hline Books & $\begin{array}{l}-0.017 \\
(0.003)\end{array}$ & $\begin{array}{l}-0.018 \\
(0.002)\end{array}$ & $\begin{array}{l}-0.021 \\
(0.002)\end{array}$ & $\begin{array}{l}-0.023 \\
(0.001)\end{array}$ & $\begin{array}{l}-0.024 \\
(0.001)\end{array}$ & {$[-0.002$} & $0.008]$ & 0.546 & 2,922 \\
\hline Sports & $\begin{array}{c}0.020 \\
(0.003)\end{array}$ & $\begin{array}{c}0.020 \\
(0.002)\end{array}$ & $\begin{array}{c}0.020 \\
(0.002)\end{array}$ & $\begin{array}{c}0.019 \\
(0.002)\end{array}$ & $\begin{array}{c}0.018 \\
(0.002)\end{array}$ & {$[0.017$, } & $0.028]$ & 0.491 & 5,796 \\
\hline Watches & $\begin{array}{c}0.000 \\
(0.001)\end{array}$ & $\begin{array}{c}0.000 \\
(0.001)\end{array}$ & $\begin{array}{c}0.000 \\
(0.001)\end{array}$ & $\begin{array}{l}0.000 \\
(0.001)\end{array}$ & $\begin{array}{c}0.000 \\
(0.001)\end{array}$ & {$[0.000$} & $0.000]$ & 0.588 & 3,156 \\
\hline Toys & $\begin{array}{c}0.016 \\
(0.000)\end{array}$ & $\begin{array}{c}0.016 \\
(0.000)\end{array}$ & $\begin{array}{c}0.016 \\
(0.000)\end{array}$ & $\begin{array}{l}0.016 \\
(0.000)\end{array}$ & $\begin{array}{c}0.016 \\
(0.000)\end{array}$ & [ 0.016 & $0.016]$ & 0.549 & 1,208 \\
\hline Computers & $\begin{array}{c}0.082 \\
(0.003)\end{array}$ & $\begin{array}{c}0.083 \\
(0.003)\end{array}$ & $\begin{array}{c}0.084 \\
(0.002)\end{array}$ & $\begin{array}{c}0.085 \\
(0.002)\end{array}$ & $\begin{array}{c}0.086 \\
(0.002)\end{array}$ & {$[0.077$, } & $0.089]$ & 0.399 & 6,350 \\
\hline
\end{tabular}

NOTE: The number of PBL approvals in the municipality measures the degree of regulation. Marginal effects are computed using percentile measures of previous productivity in each local market and year. $A C F_{l}$ is Ackerberg, Caves, and Fraser's (2006) two-step estimation method using labor as proxy for productivity; $A C F_{l m}$ is two-step estimation using a nonparametric labor demand function as proxy for productivity and controlling for imperfect competition. Productivity is recovered from the service production function: $\omega_{j t}=(\eta /(1+\eta))\left[y_{j t}-(1+1 / \eta)\left[\beta_{l} l_{j t}+\beta_{k} k_{j t}\right]+(1 / \eta) q_{m t}+(1 / \eta) \mathbf{z}_{m t}^{\prime} \boldsymbol{\beta}_{z}\right]$. 

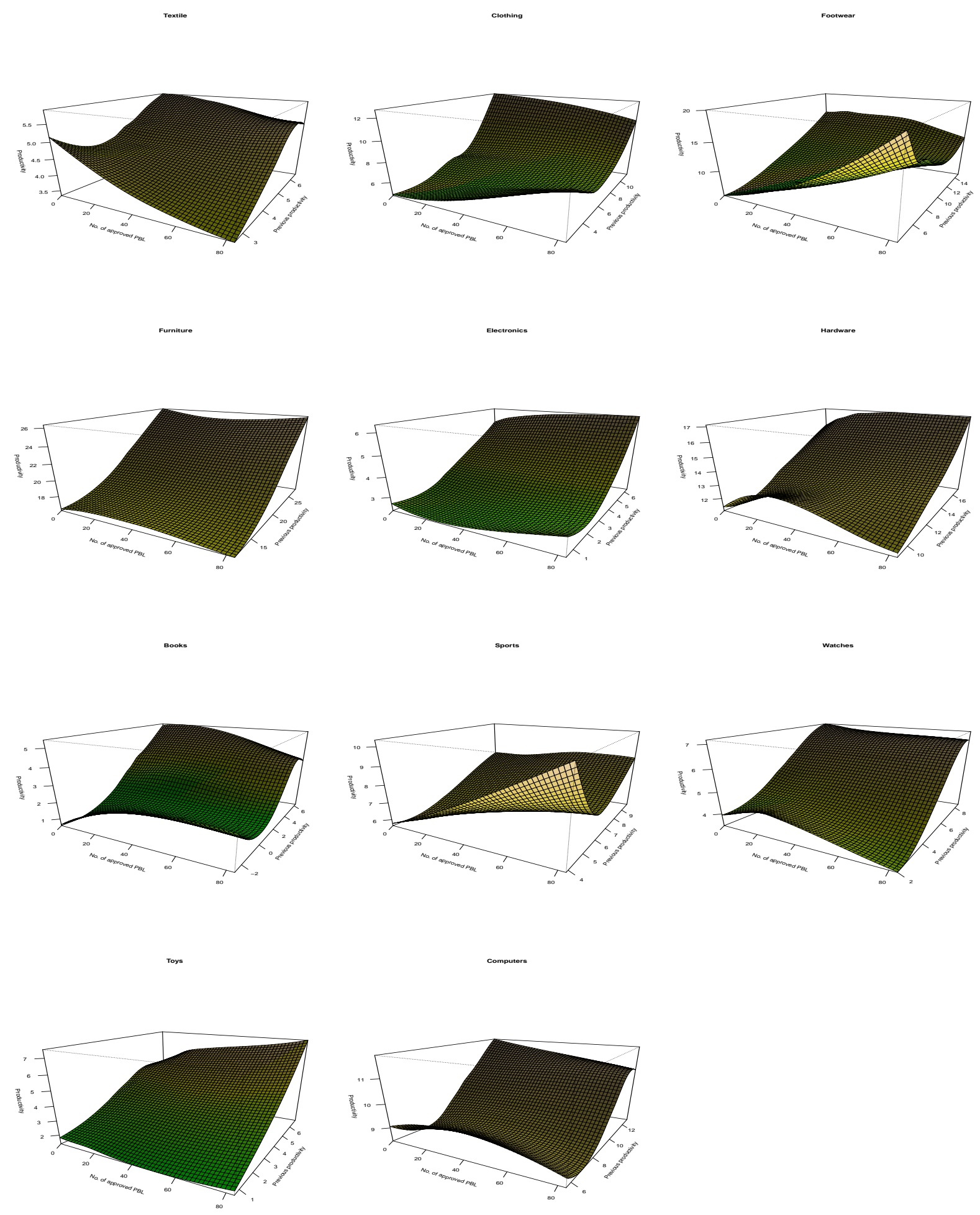

Figure 1: The industry relation between productivity, previous productivity, and number of approved PBL applications, 1996 to 2002 


\section{References}

Ackerberg, D., X. Chen, and J. Hahn (2011): "A Practical Asymptotic Variance Estimator for Two-Step Semiparametric Estimators," Discussion Paper 1803, Cowles Foundation Discussion Paper.

Ai, C., And X. Chen (2003): "Efficient Estimation of Models with Conditional Moment Restrictions Containing Unknown Functions," Econometrica, 71(6), 1795-1843.

Berry, S., J. Levinsohn, And A. Pakes (1995): "Automobile Prices in Market Equilibrium," Econometrica, 63(4), 841-890.

Bertrand, M., and F. Kramarz (2002): "Does Entry Regulation Hinder Job Creation? Evidence from the French retail industry," Quarterly Journal of Economics, $117(4), 1369-1413$.

Chen, X., And S. Ludvigson (2007): "Land of Addicts? An Empirical Investigation of Habit-Based Asset Pricing Models," Mimeo, New York University.

Doraszelski, U., and J. Jaumandreu (2013): "R\&D and Productivity: Estimating Endogenous Productivity," Review of Economic Studies, 80(4), 1338-1383.

Greenstone, M., J. List, and C. Syverson (2012): "The Effects of Environmental Regulation on the Competitiveness of U.S. Manufacturing," (Working Paper 18392, NBER).

Hulten, C., And F. Wykoff (1981): chap. The Measurement of Economic Depreciation, in C. Hulten (ed.), Depreciation, Inflation, and Taxation of Income from Capital, Urban Institute Press, Washington, D.C.

Klette, T., And Z. Griliches (1996): "The Inconsistency of Common Scale Estimators when Output Prices are Unobserved and Endogenous," Journal of Applied Econometrics, 11(4), 343-361. 
Newey, W., ANd J. Powell (2003): "Instrumental Variables Estimation of Nonparametric Models," Econometrica, 71(3), 1557-1569.

Newey, W., J. Powell, and F. Vella (1999): "Nonparametric Estimation of Triangular Simultaneous Equations Models," Econometrica, 67(3), 565-603.

Olley, S., And A. Pakes (1996): "The Dynamics of Productivity in the Telecommunications Equipment Industry," Econometrica, 64(6), 1263-1297.

Robinson, P. (1988): "Root-N-Consistent Semiparametric Regression," Econometrica, 56(4), 931-954.

SAdun, R. (2014): "Does Planning Regulation Protect Independent Retailers?," Review of Economics and Statistics (forthcoming).

Schivardi, F., and E. Viviano (2011): "Entry Barriers in Retail Trade," Economic Journal, 121(155), 145-170.

Swedish Competition Authority (2001:4): "Kan Kommunerna Pressa Matpriserna? (Can the Municipalities Put Pressure on Prices?)," Technical Report 4, Stockholm. (2004:2): "Konsumenterna, Matpriserna och Konkurrensen (Consumers, Retail Food Prices, and Competition)," Technical Report 2, Stockholm. 